\title{
Article
}

\section{Total bond order density as a quantum mechanical metric for materials design: Application to chalcogenide crystals}

\author{
Sahib Hasan ${ }^{1}$, Kagendra Baral ${ }^{2}$ Wai-Yim Ching ${ }^{2, *}$ \\ 1 Affiliation 1; sahmvd@mail.umkc.edu \\ 2 Affiliation 2; kbx67@mail.umkc.edu \\ * Correspondence: chingw@umkc.edu; Tel.: (816) 235-2503
}

\begin{abstract}
Materials design for processing and application requires fundamental understanding of their properties based interatomic interaction. The use of the novel concept of total bond order density (TBOD) as a single quantum mechanical metric to characterize the internal cohesion of a crystal and correlate with the calculated physical properties is particularly appealing. This requires detailed first-principles calculation of the electronic structure, interatomic bonding and related properties. In this article, we use this new concept and apply it to chalcogenide crystals based on data obtained from 25 crystals: $\mathrm{Ag}_{2} \mathrm{~S}, \mathrm{Ag}_{2} \mathrm{Se}, \mathrm{Ag}_{2} \mathrm{Te}, \mathrm{As}_{2} \mathrm{~S}_{3}, \mathrm{As}_{2} \mathrm{Se}_{3}, \mathrm{As}_{2} \mathrm{Te}_{3}, \mathrm{As}_{4} \mathrm{Se}_{4}, \mathrm{Cu}_{2} \mathrm{~S}, \mathrm{Cu}_{2} \mathrm{Se}_{2} \mathrm{Cu}_{2} \mathrm{Te}$, $\mathrm{Cu}_{4} \mathrm{GeS}_{4}, \mathrm{Cu}_{2} \mathrm{SnS}_{3}, \mathrm{Cu}_{2} \mathrm{SnSe}_{3}, \mathrm{GeS}_{2}, \mathrm{GeSe}_{2}, \mathrm{Ge}_{4} \mathrm{Se}_{9}, \mathrm{Sb}_{2} \mathrm{~S}_{3}, \mathrm{Sb}_{2} \mathrm{Se}_{3}, \mathrm{Sb}_{2} \mathrm{Te}_{3}, \mathrm{SnS}, \mathrm{SnSe}, \mathrm{CdSe}, \mathrm{CdTe}, \mathrm{ZnSe}$, and ZnTe. Together with the calculated optical and mechanical properties, we demonstrate the efficacy of using this novel approach for materials design that could facilitate the exploration and development of new chalcogenide crystals and glasses. Moreover, the TBOD and its partial components (PBOD) could be the key descriptors in machine learning protocol for broader scale design when a large database is available.
\end{abstract}

Key words: Chalcogenide crystals, electronic structure, optical properties, mechanical properties, total bond order density, density functional theory.

\section{Introduction}

The term "chalcogenide" comes from the Greek word "chalcos". Chalcogenides are materials containing mostly one chalcogen elements (e.g. S, Se or Te) and one or more metallic ions from group IVA and VA elements. Chalcogenides are covalently bonded materials and can be amorphous or crystalline with a band gap typically ranging from $1-3 \mathrm{eV}$. Chalcogenide glasses or crystals are very different from the traditional glasses, silica or silicates which have much wider range of band gaps close to $8 \mathrm{eV}[1]$.

Crystalline and amorphous chalcogenides are an important class of compounds very different from oxides and nitrides but relatively less studied. This can be traced to their special interatomic bonding and more diverse compositions. In the simplest binary composition between elements A and B, A can be from group IB in the Periodic Table that are noble metals $(\mathrm{Cu}, \mathrm{Ag})$, or IIB (Cd, Zn), or IVA (Ge, Sn) or VA (As, Sb) while B are chalcogene elements from group VIA ( $\mathrm{S}, \mathrm{Se}, \mathrm{Te})$. It is noted that the chalcogenide elements A and B except $\mathrm{S}$ in $\mathrm{B}$ contain filled $3 d^{10}$ or $4 d^{10}$ electron shells. It is the formation of various possible chemical bonds between $\mathrm{A}$ and $\mathrm{B}$ that makes chalcogenides a special class of materials with diverse structures and properties. The $\mathrm{A}$ elements can be extended to include other metals and form ternary or quaternary mixtures and with some of them are involved in layered 2D structures. This plethora possibility in the structure and composition of chalcogenide makes a comprehensive study on chalcogenides an extremely challenging task. Most existing researches in the literature concentrate on one or a few chalcogenide crystals or glasses. In this work, we study 25 crystals in which 22 are binary and 3 are ternary with A elements $\mathrm{Cu}, \mathrm{Ag}, \mathrm{Cd}, \mathrm{Zn}, \mathrm{Ge}, \mathrm{Sn}, \mathrm{As}, \mathrm{Sb}$ and B elements $\mathrm{S}, \mathrm{Se}, \mathrm{Te}$. In principle, the single element chalcogene S, Se and Te should be the first step to understand the chalcogenide compounds. However, these three elements have poor thermal stability [2-8]. This prompted 
researchers to mix these three elements with other metallic elements such as $\mathrm{As}, \mathrm{Ag}, \mathrm{Cu}, \mathrm{Cd}, \mathrm{Zn}, \mathrm{Ge}, \mathrm{Sb}, \mathrm{Sn}$, $\mathrm{Cd}$ and $\mathrm{Zn}$, leading to the search for binary and multicomponent chalcogenides with special properties.

Crystalline chalcogenides are transparent in mid-infrared region. This makes them good materials for infrared (IR) sensors and IR optics in communications, imaging, remote sensing and laser power delivery [9-12]. Within the last two decades, research and interest in chalcogenides have grown tremendously. Many innovative devices have been fabricated including IR optical transmitting materials, fiber optics, and integrated optical devices [13, 14]. They work efficiently at the frequency range from 1.3 to $1.55 \mu \mathrm{m}$ and meet the high performance criteria set by the telecom industry [15]. In medical field, the use of optical fibers to deliver high power laser light in surgical procedures made a huge advance. However, most of these optical fibers absorb all light in the IR region and unable to deliver a power beyond it. Thus searching for transparent materials in the IR region is crucial. Modern applications of chalcogenides include bio-sensing, tumor detection, and IR fingerprints of lung cells $[16,17]$. S and Se can detect X-ray and they have been used for X-ray digital image detector in medical tomography $[18,19]$. They are also used to make planner and channel waveguides due to their relatively high refractive index.

There are two other reasons that makes chalcogenides so important: Firstly, many crystalline and amorphous chalcogenides can coexist at same composition. Secondly, they are photo-chemical sensitive with rapidly increasing applications in technology [20]. $\mathrm{Cu}$ and $\mathrm{Ag}$ sulfides are widely used to fabricate the photon absorbers in thin films solar cell [21, 22] and in quantum dots [23, 24]. $\mathrm{Cu}_{2} \mathrm{SnS}_{3}$ and $\mathrm{Cu}_{2} \mathrm{SnSe}_{3}$ are new promising materials in for solar cells [25-27]. On the other hand, $\mathrm{GeS}_{2}$ and $\mathrm{GeSe}_{2}$ have several applications in cutoff devices and photovoltaic cells [28-30]. Recently, $\mathrm{Sb}_{2} \mathrm{~S}_{3}, \mathrm{Sb}_{2} \mathrm{Se}_{3}, \mathrm{Sb}_{2} \mathrm{Te}_{3}, \mathrm{SnS}, \mathrm{SnSe}, \mathrm{CdSe}, \mathrm{CdTe}, \mathrm{ZnSe}$, and ZnTe are all getting more attention due to their unique electrical, optical, switching and photovoltaic properties [31-33]. Fig.1 shows the whole electromagnetic spectrum where different optoelectronic applications are relevant. It also shows the relevant range where the 25 crystals we studied can be useful. They are located near the infrared region overlapping the ultraviolet region.

Over the decade, there have been extensive studies on the electronic structure and properties of chalcogenide crystals but much less on glasses. Most of these studies focus on an isolated crystalline and glass phases or a few chalcogenides. We briefly list some of these below focusing on Ag-and As- related systems. These are not meant to be exhaustive and additional discussions will be added later in Section 3. Nasr et al[34] reported the calculation of electronic structure and optical properties of crystalline $\mathrm{Ag}_{2} \mathrm{~S}$ and obtained its energy gap $\mathrm{E}_{\mathrm{g}}=$ $0.97 \mathrm{eV}$ and refractive index $n=2.469$. Fang et al. calculated $\mathrm{E}_{\mathrm{g}}$ of $\mathrm{Ag}_{2} \mathrm{Se}$ and $\mathrm{Ag}_{2} \mathrm{Te}$ to be both equal to 0.00 $\mathrm{eV}$ [35]. For $\mathrm{As}_{2} \mathrm{~S}_{3}$, Kaur et al.[36]reported $\mathrm{E}_{\mathrm{g}}=1.925 \mathrm{eV}$. The optical properties of amorphous $\mathrm{As}_{2} \mathrm{~S}_{3}$ were calculated by Synowicki et al.[37], reporting $n=2.429$. Sundaram et al [38] measured the refractive index $n$ of glassy $\mathrm{As}_{30} \mathrm{~S}_{70}$ to be between 2.40 - 2.42. and Fayek et al [39] reported the $\mathrm{E}_{\mathrm{g}}$ for $\mathrm{As}_{2} \mathrm{Se}_{3}$ and $\mathrm{As}_{2} \mathrm{Te}_{3}$ glasses to be $1.84 \mathrm{eV}$ and $0.92 \mathrm{eV}$ respectively. Aly revealed experimentally that $n$ and $\mathrm{E}_{\mathrm{g}}$ for $\mathrm{As}_{30} \mathrm{Se}_{70}$ to be 2.43 and 1.81 $\mathrm{eV}$ respectively[40]. Other experimental studies showed $\mathrm{E}_{\mathrm{g}}$ for $\mathrm{As}_{20} \mathrm{Se}_{80}$ glass is $1.84 \mathrm{eV}[41]$ and $\mathrm{As}_{2} \mathrm{Te}_{3}$ crystal is $0.32 \mathrm{eV}[42]$. All these abundant computational and experimental data reflect the vast interest on the electronic structure and optical properties of As-related chalcogenide crystals and glasses. 

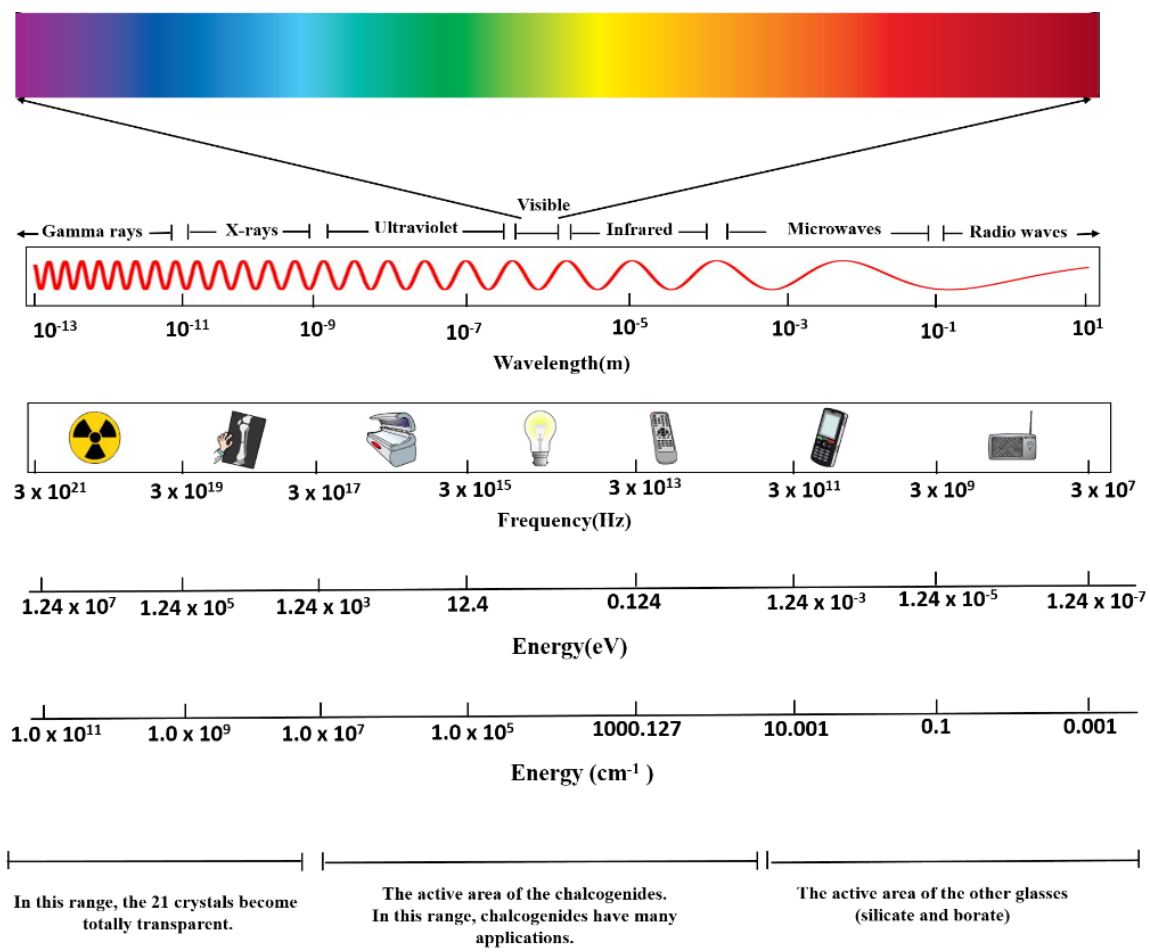

Fig. 1. The electromagnetic spectrum and active area of the chalcogenides.

The Cu-related chalcogenides have been investigated by several groups. Some of these crystals have very small or zero band gap. The $\mathrm{E}_{\mathrm{g}}$ for $\mathrm{Cu}_{2} \mathrm{Te}$ was reported by Premkumar et al [43] to be $0.0 \mathrm{eV}$ and DFT calculations by Rasander et al. [44] on $\mathrm{Cu}_{2} \mathrm{Se}$ gave $\mathrm{E}_{\mathrm{g}}=0.47 \mathrm{eV}$. Shigemi et al. showed that $\mathrm{Cu}_{2} \mathrm{SnS}_{3}$ and $\mathrm{Cu}_{2} \mathrm{SnSe}_{3}$ crystals have $\mathrm{E}_{\mathrm{g}}$ of $0.88 \mathrm{eV}$ and $0.34 \mathrm{eV}$ respectively [45]. For other chalcogenide crystals, Blaineau et al. reported $\mathrm{E}_{\mathrm{g}}$ for $\mathrm{GeS}_{2}$ glass to be $3.27 \mathrm{eV} \mathrm{[46].} \mathrm{On} \mathrm{the} \mathrm{other} \mathrm{hand,} \mathrm{Fuentes-Cabrera} \mathrm{et} \mathrm{al.[47],} \mathrm{calculated} \mathrm{E}_{\mathrm{g}}$ of crystalline $\mathrm{GeSe}_{2}$ to be $1.612 \mathrm{eV}$. Experimental studies [48-51] on $\mathrm{Ge}_{30} \mathrm{Se}_{70}, \mathrm{Ge}_{17} \mathrm{Se}_{83}, \mathrm{Ge}_{10} \mathrm{Se}_{90}$, and $\mathrm{Ge}_{14} \mathrm{Se}_{86}$ glasses assigned their $\mathrm{E}_{\mathrm{g}}$ and $n$ to be $(1.95,1.78,1.85$, and $1.82 \mathrm{eV})$ and $(2.26,2.59,2.69$, and 2.60) respectively. The $\mathrm{E}_{\mathrm{g}}$ for $\mathrm{Sb}_{2} \mathrm{~S}_{3}, \mathrm{Sb}_{2} \mathrm{Se}_{3}$ and $\mathrm{Sb}_{2} \mathrm{Te}_{3}$ crystals were reported to be $1.18 \mathrm{eV}, 1.07 \mathrm{eV}$ and $0.09 \mathrm{eV}$ respectively [52], [53]. For SnS and SnSe crystals, Guo et al. [54] reported their $\mathrm{E}_{\mathrm{g}}$ to be $1.05 \mathrm{eV}$ and $0.78 \mathrm{eV}$ respectively. M. Safari et al.[55]reported $\mathrm{E}_{\mathrm{g}}$ for CdSe, CdTe, ZnSe, and ZnTe crystals to be $0.63 \mathrm{eV}, 0.758 \mathrm{eV}, 1.276 \mathrm{eV}$, and $1.27 \mathrm{eV}$ respectively. We also found that computational studies of mechanical properties on chalcogenide crystals and glasses are quite limited despite their importance in device performance. A few older publications include amorphous $\mathrm{GeS}_{2}$ [56] and amorphous $\mathrm{GeSe}_{2}$ [57] reporting calculated values of Young's modulus, Shear modulus and Poisson's ratio.

In the present work, we have studied 25 binary and ternary chalcogenide crystals between atoms of $\mathrm{Cu}, \mathrm{Ag}, \mathrm{Cd}$, $\mathrm{Zn}, \mathrm{Ge}, \mathrm{Sn}, \mathrm{As}$, and $\mathrm{Sb}$ and chalcogene elements (S, Se, Te). They are listed in Table 1 and their crystal structures are sketched in Fig. S1 in the supplementary Information (SI).

In the following, we first briefly describe the methods used in the calculation. This is followed by the main section on the results and discussion. Detailed calculations of the electronic structure, optical and mechanical properties for these 25 chalcogenide crystals in a single paper are of considerable challenge and have not been attempted before. Such comprehensive study enables us to make meaningful correlations among different properties in getting a big picture especially in relation to a single quantum mechanical metric, the total bond order density (TBOD). The paper ends with a brief conclusion and our vision for the study of chalcogenide crystals and glasses. 


\section{Materials and Methods}

Two density functional theory (DFT) based on methods have been used in this study: Vienna Ab initio simulation package (VASP)[58] and the orthogonal linear combination of atomic orbitals (OLCAO) method[59]. VASP is used to optimize the crystal structures and calculate the mechanical properties. We used the PBE-GGA potential[60] for the exchange and correlation potential with an energy cutoff of $600 \mathrm{eV}$ and sufficient number of k-points for each crystal. For small crystals such as $\mathrm{Cu}_{2} \mathrm{Te}$, a dense k-points $(3 \times 5 \times 3$ mesh) is used and for large crystals such as $\mathrm{Cu}_{2} \mathrm{~S}$, a smaller k-point mesh or just the $\Gamma$ point in the Brillion zone are adopted using standard Monkhorst scheme[61] The electronic and ionic force convergence criteria are set at 10${ }^{6} \mathrm{eV}$ and $10^{-4} \mathrm{eV} / \AA ̊$ respectively.

For the electronic structure and optical properties calculations, we use the OLCAO package which was developed in-house with the VASP-relaxed crystal structure as input. With atomic orbitals used in the basis expansion, the OLCAO method is particularly effective to calculate the electronic structure and interatomic bonding for both crystalline and non-crystalline materials especially those with complex structures[62, 63]. For interatomic bonding, a more localized minimal basis (MB) used based on Mulliken scheme[64]. Eq. (1) and (2) show the formulae for effective charge $Q_{\alpha}^{*}$ and bond order (BO) values, or the overlap population $\rho_{\alpha \beta}$ between any pair of atoms $(\alpha, \beta)$.

$$
\begin{gathered}
Q_{\alpha}^{*}=\sum_{i} \sum_{m, o c c} \sum_{j, \beta} C_{i \alpha}^{* m} C_{j \beta}^{m} S_{i \alpha, j \beta} \\
\rho_{\alpha \beta}=\sum_{m, o c c} \sum_{i, j} C_{i \alpha}^{* m} C_{j \beta}^{m} S_{i \alpha, j \beta}
\end{gathered}
$$

In the above equation, $S_{i \alpha . j \beta}$ are the overlap integrals between the $i^{\text {th }}$ orbital in $\alpha^{\text {th }}$ atom in the $j^{\text {th }}$ orbital in $\beta^{\text {th }}$ atom. $C^{m}{ }_{j \beta}$ is the eigenvector coefficients of the $m^{\text {th }}$ occupied band. From $Q_{\alpha}^{*}$ we can obtain the so-called partial charge (PC) $\Delta Q_{\alpha}=Q_{\alpha}^{0}-Q_{\alpha}^{*}$, or the deviation from the neutral charge $Q_{\alpha}^{0}$ of atom $\alpha$. The BO from Eq. (2) defines the relative strength of the bond. The summation of all $\mathrm{BO}$ in the crystal gives the total bond order (BO). The total bond order density (TBOD) is obtained by normalizing the TBO with cell volume. TBOD is a single metric to assess the internal cohesion of the crystal. It can be conveniently decomposed into partial components or the partial bond order density (PBOD) for any structural units or groups of bonded atoms. The details for the calculation of interatomic bonding, optical and mechanical properties are described in the supplementary materials (SI).

\section{Results and Discussion}

In this section, we present the results and for the 25 chalcogenide crystals. For consistency, they are listed in the specific order following the first character of the crystal as shown in Table 1. Table 1 lists the crystal symmetry, space group and optimized parameters for each crystal. In all subsequent discussions, we follow the same order for these 25 crystals in Tables and Figures. These 25 crystals start from $\operatorname{Ag}_{2} \mathrm{X}$ where $\mathrm{X}$ is: $\mathrm{S}$, $\mathrm{Se}, \mathrm{Te}$ and end with $\mathrm{ZnX}$ where $\mathrm{X}$ is Se, Te, in this way, we can easily designate these chalcogenide crystals as $\mathrm{A}_{n} \mathrm{~B}_{\mathrm{m}}$ (where $\mathrm{n}=1,2,4,9$ and $\mathrm{m}=1,2,3,4,9$ ) where $\mathrm{A}$ is $\mathrm{Ag}$ to $\mathrm{Zn}$ atoms, and $\mathrm{B}$ is $\mathrm{S}, \mathrm{Se}$, and Te atoms. In this way, we can also easily find out the correlations between eight groups of crystals and find the changes in their physical properties when we move from Ag to Sn atom. Any deviations in the ordering will be pointed out as needed. We also pasted the rows in Table1 with different two colors (yellow and white) for 8 different groups depending on the first element for easy discussion. 
Table 1. Size and symmetry of the crystals used in our calculations and lattice parameters after full VASP relaxation, where GGA has been used as an exchange and correlation potential. (M for monoclinic, $T$ for triclinic, Tr for Trigonal, $\mathrm{O}$ for orthorhombic, and $\mathrm{C}$ for cubic.

\begin{tabular}{|c|c|c|c|c|}
\hline Crystal & $\begin{array}{l}\text { Symmetry and } \\
\text { Space group\# }\end{array}$ & $\mathbf{a}, \mathbf{b}, \mathbf{c}(\AA), \alpha, \beta, \gamma$ (in degree) & $\begin{array}{l}\text { \#of } \\
\text { Atoms }\end{array}$ & Vol. $\left(\AA^{3}\right)$ \\
\hline $\mathrm{Ag}_{2} \mathrm{~S}$ & $\mathrm{M}, \mathrm{P} 12{ }_{1} / \mathrm{c} 1(14)$ & $4.355,7.913,9.233, \alpha: 90, \beta: 122.019, \gamma: 90$ & 12 & 318.171 \\
\hline $\mathrm{Ag}_{2} \mathrm{Se}$ & $\mathrm{T}, \mathrm{P} 1(1)$ & $6.616,7.078, \quad 5.630, \alpha: 90.892, \beta: 80.305, \gamma: 90.109$ & 12 & 263.641 \\
\hline $\mathrm{Ag}_{2} \mathrm{Te}$ & $\mathrm{M}, \mathrm{P} 12{ }_{1} / \mathrm{c} 1(14)$ & $7.336,4.736,10.461, \alpha: 90, \beta: 129.788, \quad \gamma: 90$ & 12 & 363.449 \\
\hline $\mathrm{As}_{2} \mathrm{~S}_{3}$ & $\mathrm{M}, \mathrm{P} 12{ }_{1} / \mathrm{c} 1(14)$ & $4.583,10.95,12.269, \alpha: 90, \beta: 111.59, \gamma: 90$ & 20 & 615.700 \\
\hline $\mathrm{As}_{2} \mathrm{Se}_{3}$ & $\mathrm{M}, \mathrm{P} 12{ }_{1} / \mathrm{c} 1(14)$ & $4.49,10.94,12.98, \alpha: 90, \beta: 110.68, \gamma: 90$ & 20 & 615.700 \\
\hline $\mathrm{As}_{4} \mathrm{Se}_{4}$ & $\mathrm{M}, \mathrm{P} 12{ }_{1} / \mathrm{c} 1 \quad(14)$ & $7.189,14.746,10.58, \alpha: 90, \beta: 114.84, \gamma: 90$ & 32 & 1121.500 \\
\hline $\mathrm{As}_{2} \mathrm{Te}_{3}$ & $\mathrm{M}, \mathrm{C} 12 / \mathrm{m} 1(12)$ & $14.947,4.069,10.12, \alpha: 90, \beta: 95.509, \gamma: 90$ & 20 & 615.490 \\
\hline $\mathrm{Cu}_{2} \mathrm{~S}$ & $\mathrm{M}, \mathrm{P} 12{ }_{1} / \mathrm{c} 1(14)$ & $15.002,12.17,13.411, \alpha: 90, \beta: 116.603, \gamma: 90$ & 144 & 2448.500 \\
\hline $\mathrm{Cu}_{2} \mathrm{Se}$ & $\mathrm{M}, \mathrm{P} 12{ }_{1} / \mathrm{c} 1(14)$ & $6.453,4.656,6.650, \alpha: 90, \beta: 84.018, \gamma: 90$ & 12 & 199.800 \\
\hline $\mathrm{Cu}_{2} \mathrm{Te}$ & $\mathrm{M}, \mathrm{P} 12{ }_{1} / \mathrm{c} 1(12)$ & $8.213,3.827,6.153, \alpha: 90, \beta: 99.818, \gamma: 90$ & 12 & 193.395 \\
\hline $\mathrm{Cu}_{4} \mathrm{GeS}_{4}$ & $\mathrm{M}, \mathrm{P} 12{ }_{1} / \mathrm{c} 1(14)$ & $9.878,13.247,10.112, \alpha: 90, \beta: 100.572, \gamma: 90$ & 72 & 1323.194 \\
\hline $\mathrm{Cu}_{2} \mathrm{SnS}_{3}$ & $\mathrm{M}, \mathrm{C} 1 \mathrm{c} 1(9)$ & $6.699,11.693,6.738, \alpha: 90, \beta: 109.047, \gamma: 90$ & 24 & 527.797 \\
\hline $\mathrm{Cu}_{2} \mathrm{SnSe}_{3}$ & $\mathrm{M}, \mathrm{C} 1 \mathrm{c} 1(9)$ & $7.072,12.245,7.112, \alpha: 90, \beta: 109.637, \gamma: 90$ & 24 & 615.875 \\
\hline $\mathrm{GeS}_{2}$ & $\mathrm{M}, \mathrm{P} 12{ }_{1} / \mathrm{c} 1$ & $6.88,16.512,12.864, \alpha: 90, \beta: 91.08, \gamma: 90$ & 48 & 1461.380 \\
\hline $\mathrm{GeSe}_{2}$ & $\mathrm{M}, \quad \mathrm{P} 12_{1} / \mathrm{c} 1(14)$ & $7.219,17.334,13.179, \alpha: 90, \beta: 91.18, \gamma: 90$ & 48 & 1619.200 \\
\hline $\mathrm{Ge}_{4} \mathrm{Se}_{9}$ & $\mathrm{O}, \mathrm{Pca}_{1}(29)$ & $18.227,7.222,13.709, \alpha: 90, \beta: 90, \gamma: 90$ & 52 & 1804.589 \\
\hline $\mathrm{Sb}_{2} \mathrm{~S}_{3}$ & O, Pnma (62) & $12.362,3.877,11.159, \alpha: 90, \beta: 90, \gamma: 90$ & 20 & 534.822 \\
\hline $\mathrm{Sb}_{2} \mathrm{Se}_{3}$ & O, Pnma (62) & $12.901,4.074,11.299, \alpha: 90, \beta: 90, \gamma: 90$ & 20 & 593.860 \\
\hline $\mathrm{Sb}_{2} \mathrm{Te}_{3}$ & Tr, R-3m (166) & $4.329,4.329,31.535, \gamma: 120.0, \beta: 90, \alpha: 90$ & 15 & 590.973 \\
\hline $\mathrm{SnS}$ & $\mathrm{O}$, Pnma (62) & $14.46,4.114,4.108, \alpha: 90, \beta: 90, \gamma: 90$ & 8 & 244.378 \\
\hline $\mathrm{SnSe}$ & O, Pnma (62) & $4.266,4.250,14.771, \alpha: 90, \beta: 90, \gamma: 90$ & 8 & 267.805 \\
\hline $\mathrm{CdSe}$ & $\mathrm{C}, \mathrm{F}-43 \mathrm{~m}(216)$ & $6.208,6.208,6.208, \alpha: 90, \beta: 90, \gamma: 90$ & 8 & 239.250 \\
\hline $\mathrm{CdTe}$ & $\mathrm{C}, \mathrm{F}-43 \mathrm{~m}(216)$ & $6.644,6.644,6.644, \alpha: 90, \beta: 90, \gamma: 90$ & 8 & 293.280 \\
\hline $\mathrm{ZnSe}$ & C, F -4 3m (216) & $5.739,5.739,5.739, \alpha: 90, \beta: 90, \gamma: 90$ & 8 & 189.020 \\
\hline $\mathrm{ZnTe}$ & $\mathrm{C}, \mathrm{F}-43 \mathrm{~m}(216)$ & $6.189,6.189,6.189, \alpha: 90, \beta: 90, \gamma: 90$ & 8 & 237.060 \\
\hline
\end{tabular}

\subsection{Electronic structure}

The electronic structure of materials is crucial for fundamental understanding on their physical and chemical properties. The calculated results for the 25 chalcogenide crystals are shown in Figs. S2-S5 for the band structures and Figs. S6-S8 for the density of states (DOS). The calculated band gaps (Eg), direct (D) or indirect (ID) are listed in Table 2 together with other calculated and measured physical parameters that will be discussed later. The electronic structure for some selected crystals are discussed in more detailed fashion in addition to those already touched upon in the Introduction. As can be seen, $\mathrm{GeS}_{2}$ has the largest $\mathrm{E}_{\mathrm{g}}$ of $2.484 \mathrm{eV}$ among the 25 chalcogenide crystals whereas $\mathrm{Cu}_{2} \mathrm{SnSe}_{3}$ has the smallest $\mathrm{E}_{\mathrm{g}}$ of $0.015 \mathrm{eV} . \mathrm{Cu}_{2} \mathrm{Te}$ and $\mathrm{Ag}_{2} \mathrm{Te}$ are zero-gap semiconductors or semi-metals. The crystals $\mathrm{Ag}_{2} \mathrm{X}(\mathrm{X}=\mathrm{S}, \mathrm{Se}), \mathrm{As}_{2} \mathrm{X}_{3}(\mathrm{X}=\mathrm{S}, \mathrm{Se}, \mathrm{Te}), \mathrm{Sb}_{2} \mathrm{X}_{3}(\mathrm{X}=\mathrm{Se}, \mathrm{Te})$, and 
$\mathrm{As}_{4} \mathrm{Se}_{4}$ have ID gaps while the crystals $\mathrm{Cu}_{4} \mathrm{GeS}_{4}, \mathrm{GeX}_{2}(\mathrm{X}=\mathrm{S}, \mathrm{Se}), \mathrm{Sb}_{2} \mathrm{~S}_{3}, \mathrm{SnX}(\mathrm{X}=\mathrm{S}, \mathrm{Se}), \mathrm{Ge}_{4} \mathrm{Se}_{9}, \mathrm{Cu}_{2} \mathrm{X}(\mathrm{X}$ $=\mathrm{S}, \mathrm{Se}), \mathrm{CdX}(\mathrm{X}=\mathrm{Se}, \mathrm{Te})$, and $\mathrm{ZnX}(\mathrm{X}=\mathrm{Se}, \mathrm{Te})$ have direct gaps.

The following results on band gaps can be compared with other existing calculations as already mentioned in the Introduction. They are widely scattered, using different methods, approaches and potentials. Some more recent calculations are described below to compare with our calculations using OLCAO method. Since different approaches and methods are used, considerable variations are expected. To be systematic, our discussion follows the same sequence for the 25 crystals as listed in Table $\mathbf{1}$ and $\mathbf{2}$. Suarez et al. reported calculations of copper, silver and gold sulfide [74]. The $\mathrm{E}_{\mathrm{g}}$ for $\mathrm{Ag}_{2} \mathrm{~S}$ lies between $0.70-1.15 \mathrm{eV}$ compared to our value of $0.823 \mathrm{eV}$. Sharma et al [75] investigated the electronic, optical and transport properties of $\alpha$-and $\beta$-phases of arsenic telluride. The $\mathrm{E}_{\mathrm{g}}$ for $\alpha-\mathrm{As}_{2} \mathrm{Te}_{3}$ was for $0.480 \mathrm{eV}$, slightly less than our value of $0.627 \mathrm{eV}$. Xu et al. [76] used hybrid functional (HSE) potentials to report $\mathrm{E}_{\mathrm{g}}$ for monoclinic phase of $\mathrm{Cu}_{2} \mathrm{~S}$ to be $1.39 \mathrm{eV}$, much larger than our $\mathrm{E}_{\mathrm{g}}$ of $0.299 \mathrm{eV}$. Romdhane et al. [67] used the same VASP code with GGA functional getting $\mathrm{E}_{\mathrm{g}}=0.2$ $\mathrm{eV}$. After $\mathrm{GW}$ correction, a much larger $\mathrm{E}_{\mathrm{g}}$ of $0.9 \mathrm{eV}$ is obtained. This is expected since $\mathrm{GW}$ correction generally increases the band gap using DFT. Peng et al. [77] obtained $\mathrm{E}_{\mathrm{g}}=0.61 \mathrm{eV}$ for crystalline $\mathrm{Cu}_{9} \mathrm{~S}_{5}$ using a hybrid functional HSE06. This is again consistent since LDA generally underestimate $\mathrm{E}_{\mathrm{g}}$. More recently, calculations for ternary crystal $\mathrm{Cu}_{2} \mathrm{SnS}_{3}$ was reported by Crovetto et al. and also Chen and Persson [78, 79]. Similar trend is observed. Using HSE06 functional, $\mathrm{E}_{\mathrm{g}}$ was $0.83 \mathrm{eV}$ and using GGA $\mathrm{E}_{\mathrm{g}}$ was zero. Our result by using LDA has a small $\mathrm{E}_{\mathrm{g}}$ of 0.016 consistent with their calculations. Holomb et al. reported the $\mathrm{E}_{\mathrm{g}}$ for amorphous $\mathrm{GeSe}_{2}$ to be about $2.23-2.05 \mathrm{eV}$ [80]. Our calculation for crystalline $\mathrm{GeSe}_{2}$ gives $\mathrm{E}_{\mathrm{g}}=1.80 \mathrm{eV}$, indicating the $\mathrm{E}_{\mathrm{g}}$ for crystalline and amorphous chalcogenides will not differ too much. We are unable find to find any calculation on $\mathrm{Cu}_{4} \mathrm{GeS}_{4}$ and $\mathrm{Ge}_{4} \mathrm{Se}_{9}$. Apparently, our results on these two crystals are the first time results which give $\mathrm{E}_{\mathrm{g}}$ of $0.201 \mathrm{eV}$ and $1.375 \mathrm{eV}$ respectively.

Table2. OLCAO results for the 25 crystals: energy gap $\left(\mathbf{E}_{\mathrm{g}}\right)$, total bond order density (TBOD), refractive index $(n)$, the plasma frequency $\left(\omega_{p}\right)$, and the average effective charge on each atoms $\left(Q^{*}\right)$. The second column is our results, while the third column is the previous results, where $(T)$ is for calculations and $(E)$ for experimental results. (D) Stands for direct band gap, while (ID) stands for indirect band gap.

\begin{tabular}{|l|l|l|l|c|c|}
\hline $\mathbf{C r y s t a l}$ & $\mathbf{E}_{\mathbf{g}}(\mathbf{e V})$ & $\mathbf{E}_{\mathbf{g}}(\mathbf{e V})(\mathbf{o t h e r s})$ & $\mathbf{Q}^{*}\left(\mathbf{i n ~} \mathbf{e}^{-}\right)$ & $\mathbf{T B O D}\left(\mathbf{e}^{-} / \AA^{3}\right)$ & $\mathbf{n}, \boldsymbol{\omega}_{\mathbf{p}}(\mathbf{e V})$ \\
\hline $\mathrm{Ag}_{2} \mathrm{~S}$ & $0.823(\mathrm{ID})$ & $0.97[65](\mathrm{T}-\mathrm{D})$ & $10.858(\mathrm{Ag}), 6.283(\mathrm{~S})$ & 0.01394 & $2.960,19.99$ \\
\hline $\mathrm{Ag}_{2} \mathrm{Se}$ & $0.298(\mathrm{ID})$ & $0.00[35](\mathrm{T})$ & $10.875(\mathrm{Ag}), 6.248(\mathrm{Se})$ & 0.01455 & $4.580,18.49$ \\
\hline $\mathrm{Ag}_{2} \mathrm{Te}$ & 0.000 & $0.00[35](\mathrm{T})$ & $11.005(\mathrm{Ag}), 5.990(\mathrm{Te})$ & 0.01412 & $4.700,16.49$ \\
\hline $\mathrm{As}_{2} \mathrm{~S}_{3}$ & $1.906(\mathrm{ID})$ & $1.925[36](\mathrm{T}-\mathrm{ID})$ & $4.506(\mathrm{As}), 6.329(\mathrm{~S})$ & 0.0059 & $2.290,18.19$ \\
\hline $\mathrm{As}_{2} \mathrm{Se}_{3}$ & $1.523(\mathrm{ID})$ & $1.84[39](\mathrm{E}), 1.10[66](\mathrm{E})$ & $4.664(\mathrm{As}), 6.223(\mathrm{Se})$ & 0.0058 & $3.090,18.29$ \\
\hline $\mathrm{As}_{4} \mathrm{Se}_{4}$ & $1.494(\mathrm{ID})$ & $1.20[66](\mathrm{E})(\mathrm{glass})$ & $4.809(\mathrm{As}), 6.190(\mathrm{Se})$ & 0.00717 & $2.770,17.69$ \\
\hline $\mathrm{As}_{2} \mathrm{Te}_{3}$ & $0.627(\mathrm{ID})$ & $0.92[39](\mathrm{E})$ & $4.951(\mathrm{As}), 6.032(\mathrm{Te})$ & 0.00508 & $6.010,17.49$ \\
\hline $\mathrm{Cu}_{2} \mathrm{~S}$ & $0.299(\mathrm{D})$ & $0.20[67], 0.90[67](\mathrm{T}-\mathrm{D})$ & $10.908(\mathrm{Cu}), 6.182(\mathrm{~S})$ & 0.02566 & $3.670,20.99$ \\
\hline $\mathrm{Cu}_{2} \mathrm{Se}$ & $0.530(\mathrm{D})$ & $0.47[44](\mathrm{T}-\mathrm{D})$ & $10.984(\mathrm{Cu}), 6.030(\mathrm{Se})$ & 0.02225 & $4.120,19.99$ \\
\hline $\mathrm{Cu}_{2} \mathrm{Te}$ & 0.000 & $0.00[43](\mathrm{T})$ & $11.158(\mathrm{Cu}), 5.683(\mathrm{Te})$ & 0.02858 & $5.470,16.99$ \\
\hline $\mathrm{Cu}_{4} \mathrm{GeS}_{4}$ & $0.201(\mathrm{D})$ & - & $10.930(\mathrm{Cu}), 3.384(\mathrm{Ge}), 6.223(\mathrm{~S})$ & 0.02234 & $3.430,20.19$ \\
\hline $\mathrm{Cu}_{2} \mathrm{SnS}_{3}$ & 0.016 & $0.34[45](\mathrm{T})$ & $11.027(\mathrm{Cu}), 3.070(\mathrm{Sn}), 6.291(\mathrm{~S})$ & 0.01996 & $3.930,19.49$ \\
\hline $\mathrm{Cu}_{2} \mathrm{SnSe}_{3}$ & 0.015 & $0.88[45](\mathrm{T})$ & $11.047(\mathrm{Cu}), 3.274(\mathrm{Sn}), 6.210(\mathrm{Se})$ & 0.01703 & $4.410,18.99$ \\
\hline
\end{tabular}




\begin{tabular}{|l|l|l|l|c|c|}
\hline $\mathrm{GeS}_{2}$ & $2.484(\mathrm{D})$ & $3.27[46](\mathrm{T})(\mathrm{glass})$ & $3.337(\mathrm{Ge}), 6.331(\mathrm{~S})$ & 0.01178 & $2.280,17.99$ \\
\hline $\mathrm{GeSe}_{2}$ & $1.800(\mathrm{D})$ & $1.612[47](\mathrm{T}-\mathrm{D}), 2.14[68](\mathrm{E})$ & $3.534(\mathrm{Ge}), 6.232(\mathrm{Se})$ & 0.00989 & $2.450,17.49$ \\
\hline $\mathrm{Ge}_{4} \mathrm{Se}_{9}$ & $1.375(\mathrm{D})$ & - & $3.554(\mathrm{Ge}), 6.198(\mathrm{Se})$ & 0.00932 & $2.480,17.99$ \\
\hline $\mathrm{Sb}_{2} \mathrm{~S}_{3}$ & $1.050(\mathrm{D})$ & $1.18[52](\mathrm{T}-\mathrm{D}), 1.1[69](\mathrm{T}-\mathrm{D})$ & $4.242(\mathrm{Sb}), 6.505(\mathrm{~S})$ & 0.00604 & $3.780,18.29$ \\
\hline $\mathrm{Sb}_{2} \mathrm{Se}_{3}$ & $0.550(\mathrm{ID})$ & $0.99[52](\mathrm{T}-\mathrm{ID}), 0.75[69](\mathrm{T})$ & $4.362(\mathrm{Sb}), 6.425(\mathrm{Se})$ & 0.00535 & $4.310,17.99$ \\
\hline $\mathrm{Sb}_{2} \mathrm{Te}_{3}$ & $0.236(\mathrm{ID})$ & $0.136[70](\mathrm{T}-\mathrm{ID}), 0.12[71](\mathrm{T}-\mathrm{D})$ & $4.637(\mathrm{Sb}), 6.241(\mathrm{Te})$ & 0.00471 & $7.070,17.39$ \\
\hline $\mathrm{SnS}$ & $0.112(\mathrm{D})$ & $0.58[72](\mathrm{T}-\mathrm{D})$ & $3.481(\mathrm{Sn}), 6.518(\mathrm{~S})$ & 0.00534 & $5.010,16.29$ \\
\hline $\mathrm{SnSe}$ & $0.092(\mathrm{D})$ & $0.22[72](\mathrm{T}-\mathrm{ID})$ & $3.525(\mathrm{Sn}), 6.474(\mathrm{Se})$ & 0.00509 & $5.650,14.99$ \\
\hline $\mathrm{CdSe}$ & $1.64(\mathrm{D})$ & $0.71[73](\mathrm{T}-\mathrm{D})$ & $0.584(\mathrm{Cd}), 7.415(\mathrm{Se})$ & 0.00473 & $2.29,17.89$ \\
\hline $\mathrm{CdTe}$ & $1.97(\mathrm{D})$ & $0.61[73](\mathrm{T}-\mathrm{D})$ & $0.626(\mathrm{Cd}), 7.374(\mathrm{Te})$ & 0.00399 & $2.35,16.1$ \\
\hline $\mathrm{ZnSe}$ & $1.57(\mathrm{D})$ & $1.29[73](\mathrm{T}-\mathrm{D})$ & $11.705(\mathrm{Zn}), 6.294(\mathrm{Se})$ & 0.02016 & $2.7,17.4$ \\
\hline $\mathrm{ZnTe}$ & $1.92(\mathrm{D})$ & $1.23[73](\mathrm{T}-\mathrm{D})$ & $11.95(\mathrm{Zn}), 6.05(\mathrm{Te})$ & 0.01786 & $2.8,16.5$ \\
\hline
\end{tabular}

In other chalcogenide crystals, Ibanez et al. [69] reported the $\mathrm{E}_{\mathrm{g}}$ of $1.1 \mathrm{eV}$ and $0.75 \mathrm{eV}$ for crystalline $\mathrm{Sb}_{2} \mathrm{~S}_{3}$ and $\mathrm{Sb}_{2} \mathrm{Se}_{3}$ respectively. Our calculated $\mathrm{E}_{\mathrm{g}}$ for these two crystals are 1.05 and $0.55 \mathrm{eV}$. Nasr et al. [81] obtained $\mathrm{E}_{\mathrm{g}}$ for $\mathrm{Sb}_{2} \mathrm{~S}_{3}$ to be $1.88 \mathrm{eV}$, higher than ours. For crystalline $\mathrm{Sb}_{2} \mathrm{Se}_{3}$, Cao et al. [82] obtained $\mathrm{E}_{\mathrm{g}}$ of $0.19 \mathrm{eV}$ by including vdW interactions, much less than our value of $0.55 \mathrm{eV}$. For crystalline $\mathrm{Sb}_{2} \mathrm{Te}_{3}$, the $\mathrm{E}_{\mathrm{g}}$ obtained by using GGA and GGA + vdW are $0.036 \mathrm{eV}$ and $0.136 \mathrm{eV}$ respectively [70, 83] while another study [71] gave $\mathrm{E}_{\mathrm{g}}$ $=0.12 \mathrm{eV}$ for $\mathrm{Sb}_{2} \mathrm{Te}_{3}$. Kumagai et al. [84] did calculations for crystalline $\mathrm{SnS}$ using different exchangecorrelation functions. The $\mathrm{E}_{\mathrm{g}}$ was $0.44 \mathrm{eV}$ with LDA, $0.89 \mathrm{eV}$ with GGA and $1.29 \mathrm{eV}$ using HSE06. Another study [72] reported the $\mathrm{E}_{\mathrm{g}}$ for the $\mathrm{SnS}$ and $\mathrm{SnSe}$ to be $0.58 \mathrm{eV}$ and $0.22 \mathrm{eV}$ respectively. Our values for these two crystals are 0.112 and $0.092 \mathrm{eV}$ respectively. For $\mathrm{Sb}_{2} \mathrm{Te}_{3}$ crystal, Zhang et al.[85] reported $\mathrm{E}_{\mathrm{g}}$ of $0.746 \mathrm{eV}$ using GGA approximation. Z. Nourbakhsh[73] calculated the $\mathrm{E}_{\mathrm{g}}$ for the cubic crystals of CdSe, CdTe, ZnSe and ZnTe using GGA to be $0.71,0.61,1.29$, and $1.23 \mathrm{eV}$ respectively. Our calculated $\mathrm{E}_{\mathrm{g}}$ values for CdSe and CdTe crystals are 1.64 and $1.97 \mathrm{eV}$ respectively, much closer to experimental values of $1.75 \mathrm{eV}$ [73] and 1.61 $\mathrm{eV}$ [86] respectively.

On the experimental side, Zhao et al. carried out IR measurements with photon energy ranging from 0.08-1.0 $\mathrm{eV}$ for $\mathrm{Ag}_{2} \mathrm{Se}$ crystal [87]. They concluded that it is a narrow gap semiconductor which is consistent with our calculated gap value of $0.298 \mathrm{eV}$. In a joint experimental and computational study for glassy $\mathrm{As}_{2} \mathrm{Se}_{3}$ and $\mathrm{As}_{4} \mathrm{Se}_{4}$ by Li et al. [66], the reported $\mathrm{E}_{\mathrm{g}}$ for glassy $\mathrm{As}_{4} \mathrm{Se}_{4}\left(\mathrm{As}_{2} \mathrm{Se}_{3}\right)$ is about $1.20 \mathrm{eV}(1.10 \mathrm{eV})$ compared to our values of $1.494 \mathrm{eV}$ and $1.523 \mathrm{eV}$ for $\mathrm{As}_{4} \mathrm{Se}_{4}$ and $\mathrm{As}_{2} \mathrm{Se}_{3}$ respectively. Recently, Vaney et al [88] in a combined computational and experiment investigation of $\alpha-\mathrm{As}_{2} \mathrm{Te}_{3}$ reported its $\mathrm{E}_{\mathrm{g}}$ to be $0.300 \mathrm{eV}$ from calculation and $0.430 \mathrm{eV}$ from experiment. Our calculated value of $0.627 \mathrm{eV}$ for $\mathrm{As}_{2} \mathrm{Te}_{3}$ is almost twice as large. A recent by experimental study using optical transmission spectra has been conducted by Pan et al. to investigate $\mathrm{E}_{\mathrm{g}}$ of amorphous $\mathrm{GeSe}_{2}$ [68]. The reported value of $2.14 \mathrm{eV}$ is slightly larger than our calculated value of $1.800 \mathrm{eV}$. The experimental values of $\mathrm{E}_{\mathrm{g}}$ for crystals $\mathrm{Sb}_{2} \mathrm{~S}_{3}, \mathrm{Sb}_{2} \mathrm{Se}_{3}$, and $\mathrm{Sb}_{2} \mathrm{Te}_{3}$ by Olson et al. [89] are $1.7 \mathrm{eV}, 1.2 \mathrm{eV}$ and $0.15-0.2 \mathrm{eV}$ respectively. These values for $\mathrm{Sb}_{2} \mathrm{~S}_{3}$ and $\mathrm{Sb}_{2} \mathrm{Se}_{3}$ are larger than our calculated values, while for the $\mathrm{Sb}_{2} \mathrm{Te}_{3}$, it is close to our result of $0.236 \mathrm{eV}$. Zhao [90] reported the experimental $\mathrm{E}_{\mathrm{g}}$ for $\mathrm{SnSe}$ crystal to be $0.86 \mathrm{eV}$. 
The comparative results described above are all listed in Table 2 with the references cited. It should again be stressed that in this work, the calculation on the 25 crystals using the same method and potential can provide meaningfully correlations of the results.

\subsection{Interatomic bonding}

One of the most useful results from the OLCAO calculation is the interatomic bonding between every pair of atoms in the crystal and their bond order (BO) values which signifies the strength of the bond. By dividing the sum of all BO values by the volume of the cell, we get the total bond order density (TBOD), a single parameter to assess the internal cohesion and strength of the crystal [91]. The TBOD concept is particularly useful in the present case since the data from 25 crystals over a variety of bonding configurations in different crystal types can be compared. In Fig. 2, we plotted the distribution of BO vs bond length (BL) for all atomic pairs in all 25 crystals. Obviously, this is a very busy figure that cannot reveal any pertinent details to draw useful conclusions other than the general observation that BO usually scales with the BL. There are 36 different types of bond pairs and the BO vs BL in each pairs can vary significantly. To dig out more details for specific trends related to each atomic species and the crystal structure they belong, we divide them into 10 groups as shown in the insects of Fig. 2. Please note that the groups (a), (b), (c), (d), (e) contain same atomic pairs but from different crystals. The BO vs BL plots of these 10 groups are displayed in Figs. S9, S10 and S11 from (a) - (j) using the same scales for $\mathrm{x}$ - and $\mathrm{y}$-axis as in Fig.2. Such detailed plots disentangle the complexity of Fig. 2 and provide new insights which are separately discussed in the first section in SI.

The TBOD is a single quantum mechanical metric obtained from the electronic structure calculations characterizing the internal cohesion of the materials based on their interatomic interaction (BO) and the equilibrium structure (volume). Thus the TBOD for each crystal is determined by strength of the bonds it contains and the equilibrium structure of the crystal. The highest TBOD in the 25 crystals is $\mathrm{Cu}_{2} \mathrm{Te}$ followed by $\mathrm{Cu}_{2} \mathrm{~S}$ and the lowest TBOD is from CdTe closely followed by $\mathrm{Sb}_{2} \mathrm{Te}_{3}$ and $\mathrm{As}_{2} \mathrm{Te}_{3}$ (see Table 2).

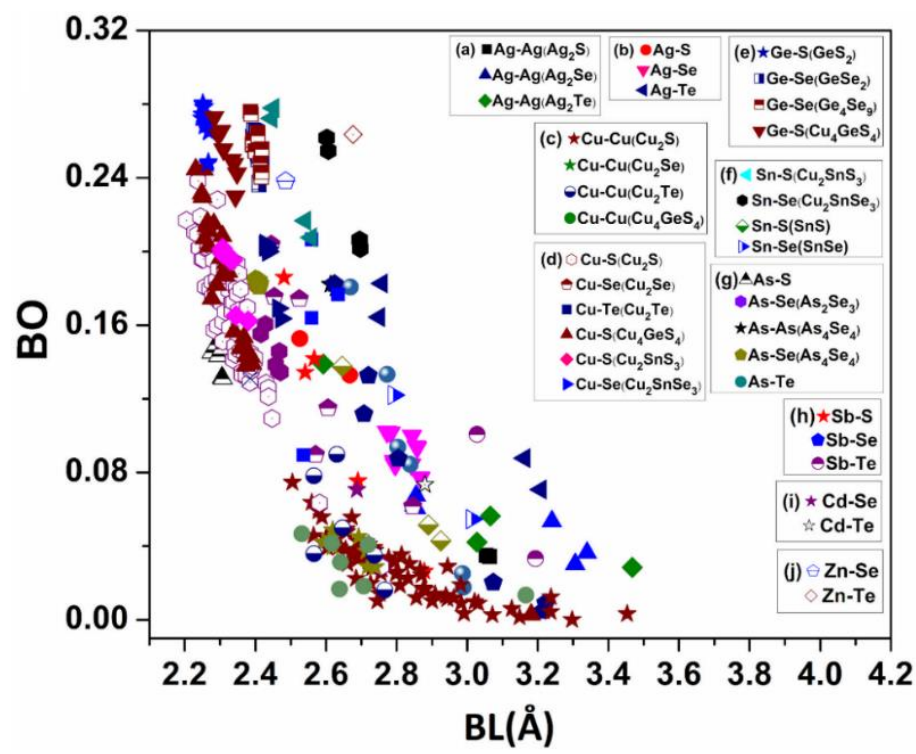

Fig. 2. BL vs BO for all 25 crystals. 
In Fig. 3 we display the TBOD for the 25 crystals in the sequential order as designated earlier for Table 1. They can be roughly divided into 8 groups according to the element $\mathrm{A}$ in the crystal formula (Ag, $\mathrm{As}, \mathrm{Cu}, \mathrm{Ge}, \mathrm{Sb}, \mathrm{Sn}$, $\mathrm{Cd}$ and $\mathrm{Zn}$ ) as indicated by the horizontal bars on top of the histogram plot. Within each group, the TBOD can vary especially for $\mathrm{A}=\mathrm{Cu}$. Such variations are much smaller in other 7 groups. Thus we have the conclusion the groups with $\mathrm{A}=\mathrm{Cu}$ group has the highest TBOD on average followed by the $\mathrm{A}=\mathrm{Zn}$ and $\mathrm{Ag}$, then Ge. The lowest average TBOD groups are $\mathrm{A}=\mathrm{Cd}, \mathrm{Sn}$, and $\mathrm{Sb}$ in that order. The minor variations within each group is controlled by the chalcogenide $\mathrm{B}$ element $\mathrm{S}$, Se and Te. The large variations in TBOD in the $\mathrm{A}=\mathrm{Cu}$ group can be attributed to the large variations in their crystal volume. Thus we reach one important conclusion that the strength of binary chalcogenide crystals is dictated mostly by the element A and much less by the element B.

\subsection{Partial charge}

The partial charge (PC) distributions in chalcogenide crystals are important information related to charge transfer and interatomic bonding. The general accepted concept is that chalcogene elements (B) receive electrons from (A) elements or equivalently, A is electropositive and B is electronegative and they form strong covalent bonds with ionic characters. It turns out this picture is over simplified. With 25 chalcogenide crystals formed by 11 different elements, we are in position to analyze the PC distribution and charge transfer mechanism in much greater detail than in the study of just one or few crystals. In Fig. 4 (a) and 4 (b), we plotted the calculated partial charge of A elements (Ag, As, Cu, Ge, Sb, Sn, Cd, Zn) and B elements (S, Se, Te) respectively.

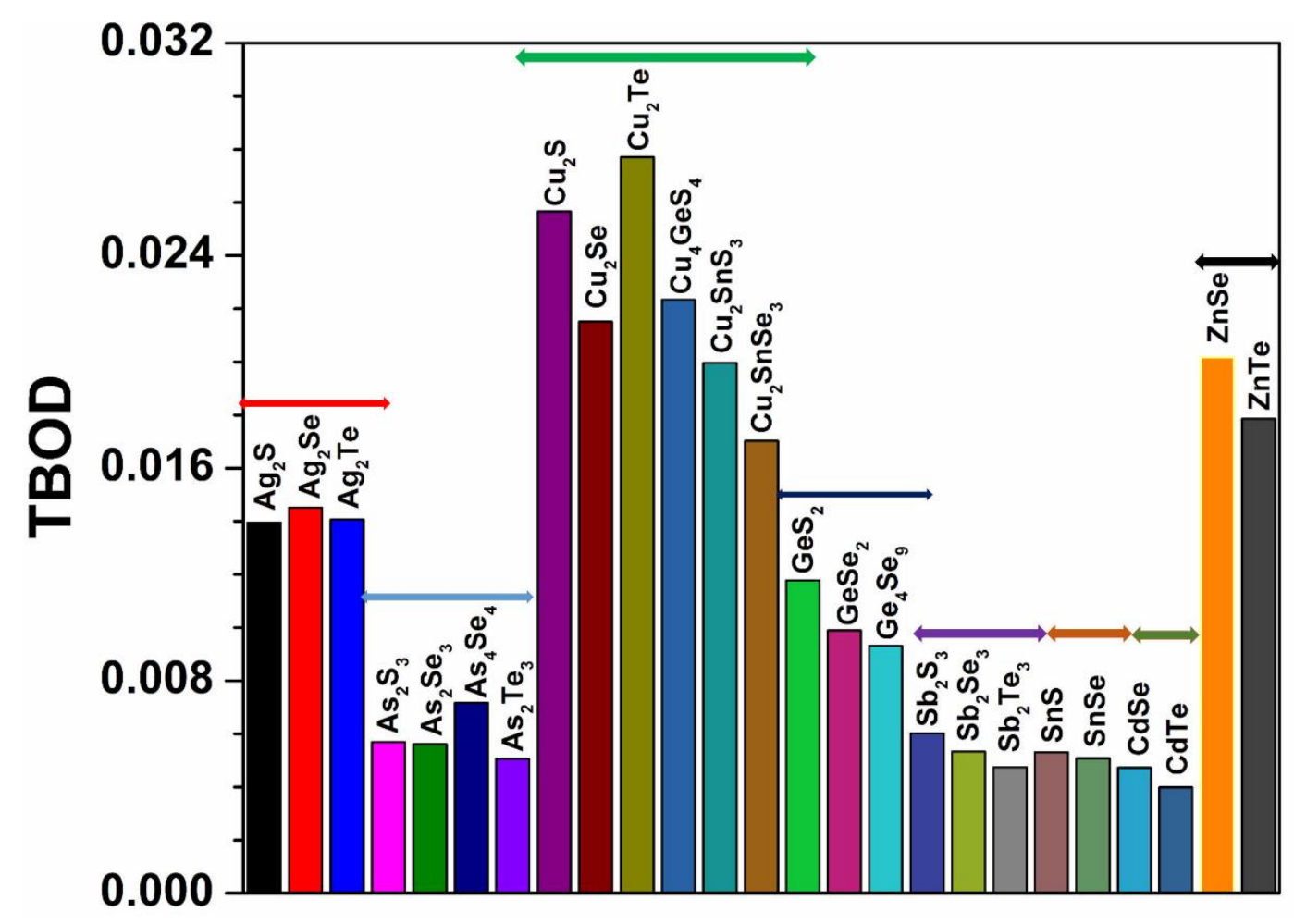

Fig.3. Distribution of the calculated total bond order density for the 25 crystals. 
In general, A elements are electropositive and B elements are electronegative as expected and their values distribute over a wide range depending on the crystals they originate from. On average, the PC value for A elements increases from $\mathrm{Ag}$ to $\mathrm{Cd}$, (except for the element $\mathrm{Cu}$, which has much less $\mathrm{PC}$ ), and they decrease (less negative) in B elements from $\mathrm{S}$ to Se to Te. The most astonishing observation to this general trend is that $\mathrm{Cu}$ from $\mathrm{Cu}_{2} \mathrm{Te}$ is actually electronegative with corresponding Te in this crystal electropositive (and to a much less extent, in $\mathrm{Cu}_{2} \mathrm{Se}$ crystal as well). This could be related to the very large size of the Te atom and they form the $\mathrm{Cu}$-Te bond with reversed mode of charge transfer. $\mathrm{Cd}$ element loses more charge than the all other $\mathrm{A}$ elements, which is very unique property for $\mathrm{Cd}$. We are not aware if this new discovery has been reported in any previous computational or experimental studies.

\subsection{Optical properties}

The optical properties of these 25 chalcogenide crystals are particularly important because of their many applications mentioned previously. They can be calculated relatively easily within the one-electron random phase approximation using the OLCAO method. The mathematical formulae involved are explained in Section 2 in SI. The calculated real and imaginary parts of the dielectric functions for these crystals are shown in Figs. 5 (a-f), 6 (g-l), 7(m-r) and 8(s-y) refractive indices are listed in Table 2. As can be seen, each crystal has its unique absorption features, we can only selectively discuss some of them focusing on those crystals having large refractive indices, and those that deem to be particularly interesting. 


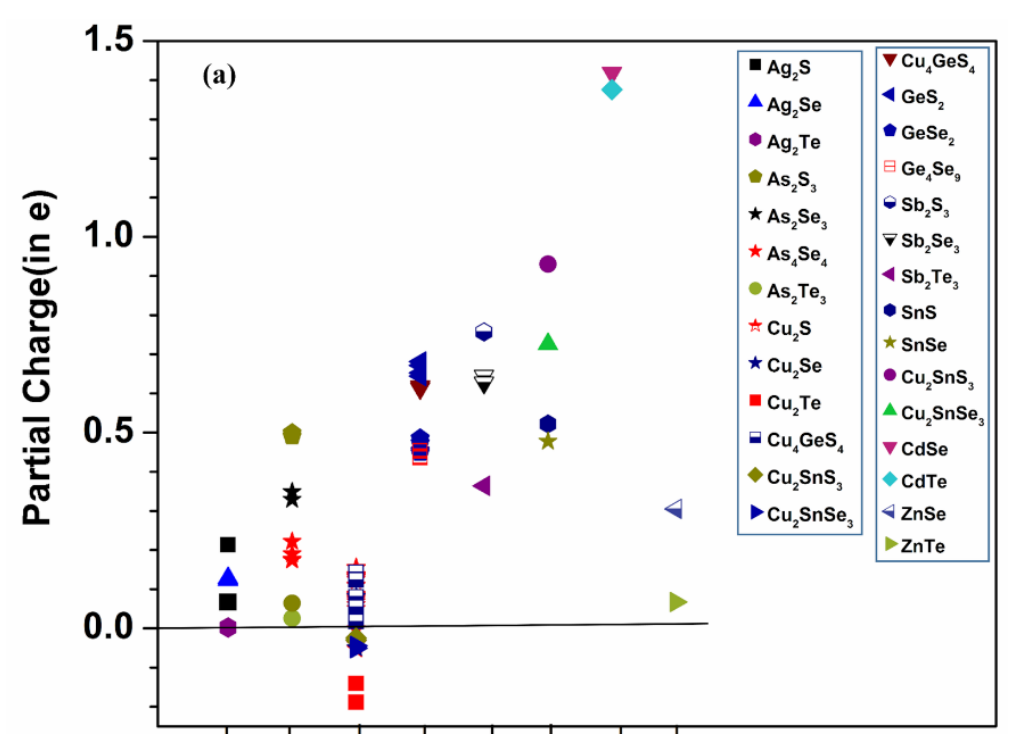

Ag Ás Cu Ge Sb Sn Cd Zn

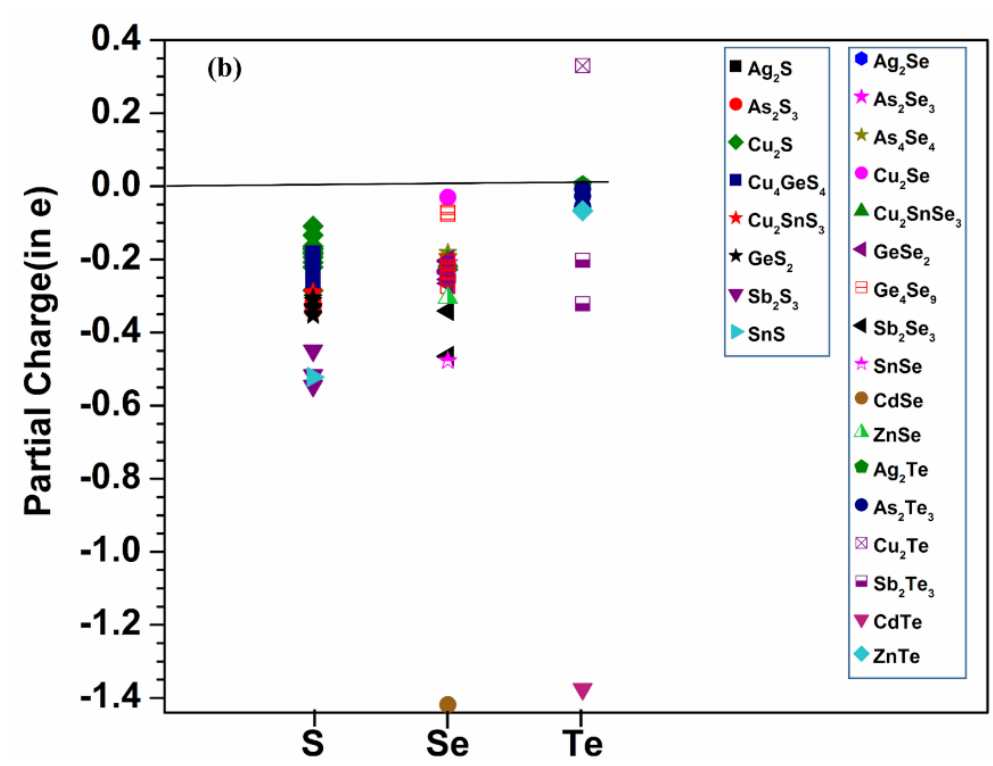

Fig. 4(a): The partial charge for $\mathrm{Ag}, \mathrm{As}, \mathrm{Cu}, \mathrm{Ge}, \mathrm{Sb}, \mathrm{Sn}, \mathrm{Cd}$, and $\mathrm{Zn}$ elements, (b): The partial charge of the chalcogene elements $(\mathrm{S}, \mathrm{Se}, \mathrm{Te})$ in the all 25 crystals. Different symbol and color indicate the crystal is belong.

The complex dielectric functions of $\mathrm{As}_{2} \mathrm{Te}_{3}$ are shown in Fig. $\mathbf{6}(\mathrm{g})$. The absorption edge of $\varepsilon_{2}(\omega)$ occurs at 0.627 $\mathrm{eV}$ consistent with the direct optical gap. The maximum peak of $\varepsilon_{2}(\omega)$ is at $2.0 \mathrm{eV}$, while the peak in real part $\varepsilon_{1}(\omega)$ is at $0.9 \mathrm{eV}$. Since the refractive index $n$ for the crystal is approximated as $\sqrt{\varepsilon_{1}}(0)$, the lower location of the major peak in $\varepsilon_{1}(\omega)$ results in a relatively high refractive index for $\mathrm{As}_{2} \mathrm{Te}_{3}(n=6.01)$. The calculated optical properties of $\mathrm{Cu}_{2} \mathrm{Te}$ is shown in Fig. $\mathbf{6}(\mathbf{j})$. Results in Table 2 shows $\mathrm{Cu}_{2} \mathrm{Te}$ is a semimetal with zero gap, so $\varepsilon_{2}(\omega)$ starts at $0.0 \mathrm{eV}$, and quickly reaches peak maximum at $0.28 \mathrm{eV}$ and the $n$ is 5.47. For the $\mathrm{Sb}_{2} \mathrm{Te}_{3}$ crystal, it has a small optical band gap of $0.238 \mathrm{eV}, \varepsilon_{2}(\omega)$ peaks at about $1.65 \mathrm{eV}$ as shown in Fig. 8(s) and it has the largest refractive index of $n=7.07$ among the 25 crystals. For SnS with an indirect band gap, $\varepsilon_{2}(\omega)$ starts at $0.112 \mathrm{eV}$ as shown in $(\mathbf{F i g . ~ 8 ( t ) )})$. It goes up rapidly reaching a maximum at $1.4 \mathrm{eV}$. On the other hand, the highest peak in $\varepsilon_{1}(\omega)$ is at $1.0 \mathrm{eV}$. So $\mathrm{SnS}$ also has a high refractive index $(n=5.01)$. Similarly for SnSe in Fig. $\mathbf{8}(\mathbf{u}), \varepsilon_{2}(\omega)$ starts at $0.092 \mathrm{eV}$ with a maximum at $1.2 \mathrm{eV}$. The KK-transformed $\varepsilon_{1}(\omega)$ has the lowest sharp peak at $1.15 \mathrm{eV}$, resulting in a very high $n=5.65$. 

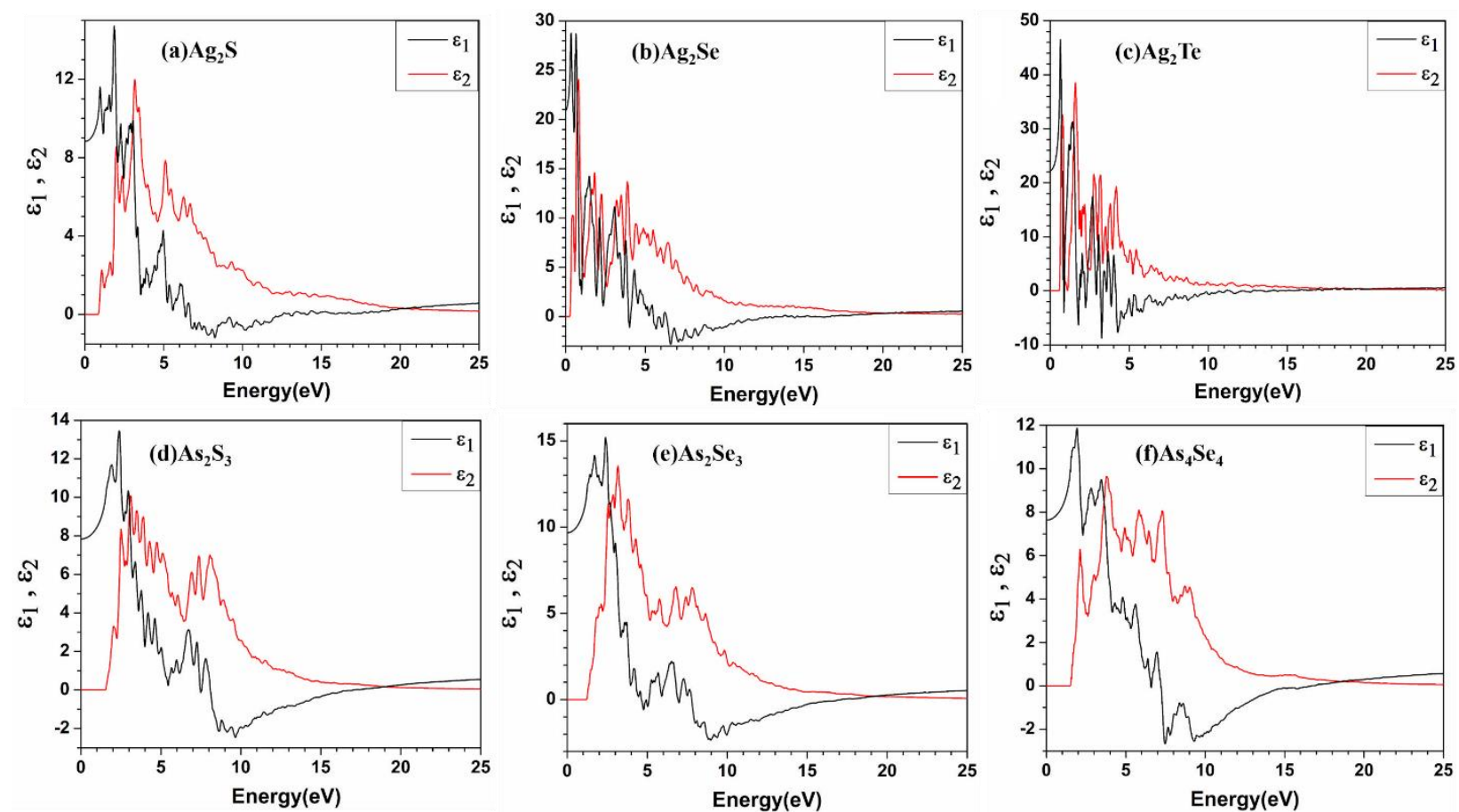

Fig.5. Optical dielectric function for the crystals from (a) $\mathrm{Ag}_{2} \mathrm{~S}$ to (f) $\mathrm{As}_{4} \mathrm{Se}_{4}$. The black curve for the real part $\left(\varepsilon_{1}\right)$, the red curve for the imaginary part $\left(\varepsilon_{2}\right)$.
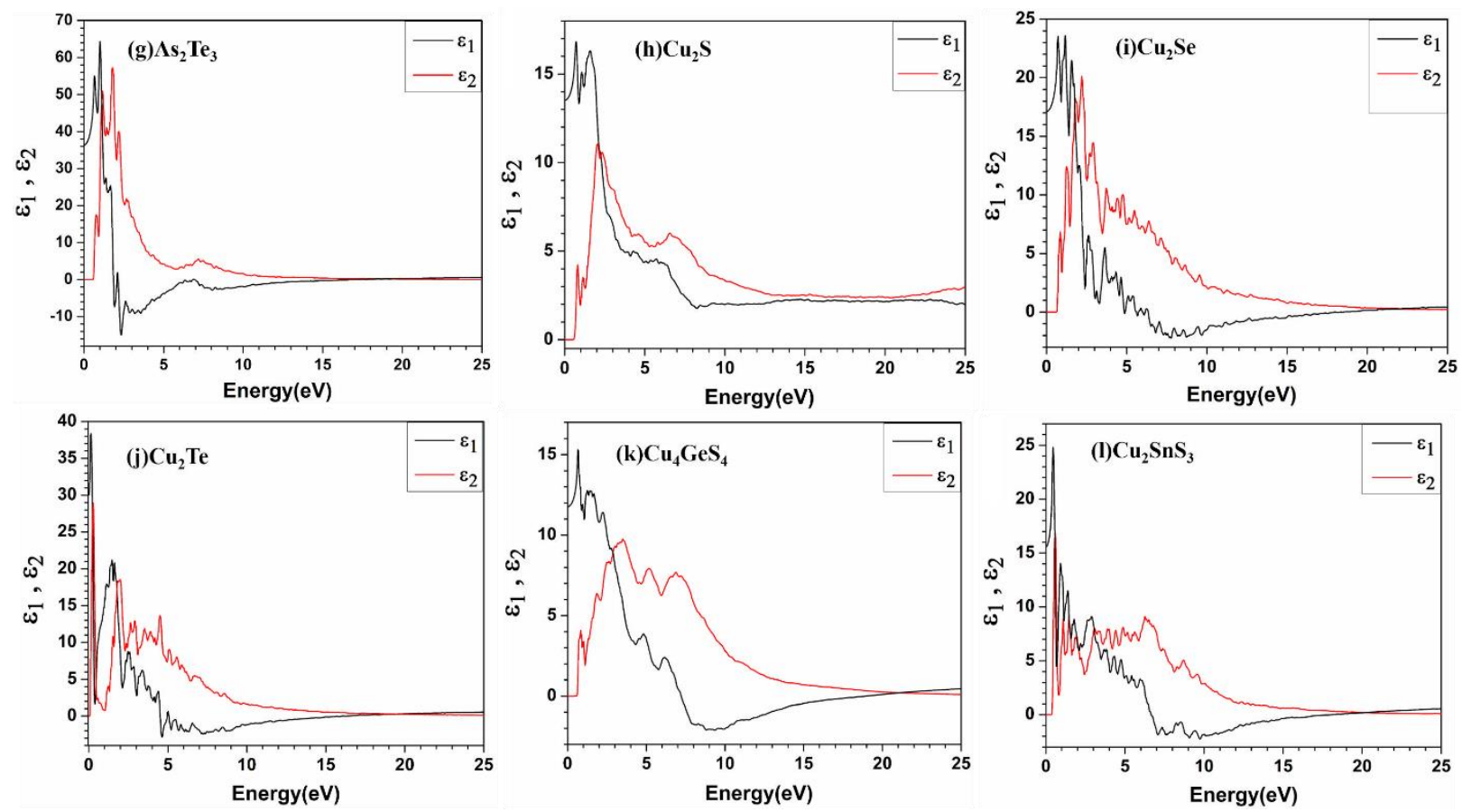

Fig.6. Optical dielectric function for the crystals from (g) Ass $\mathrm{Te}_{3}$ to (l) $\mathrm{Cu}_{2} \mathrm{SnS}_{3}$. The black curve for the real part $\left(\varepsilon_{1}\right)$, the red curve for the imaginary part $\left(\varepsilon_{2}\right)$. 

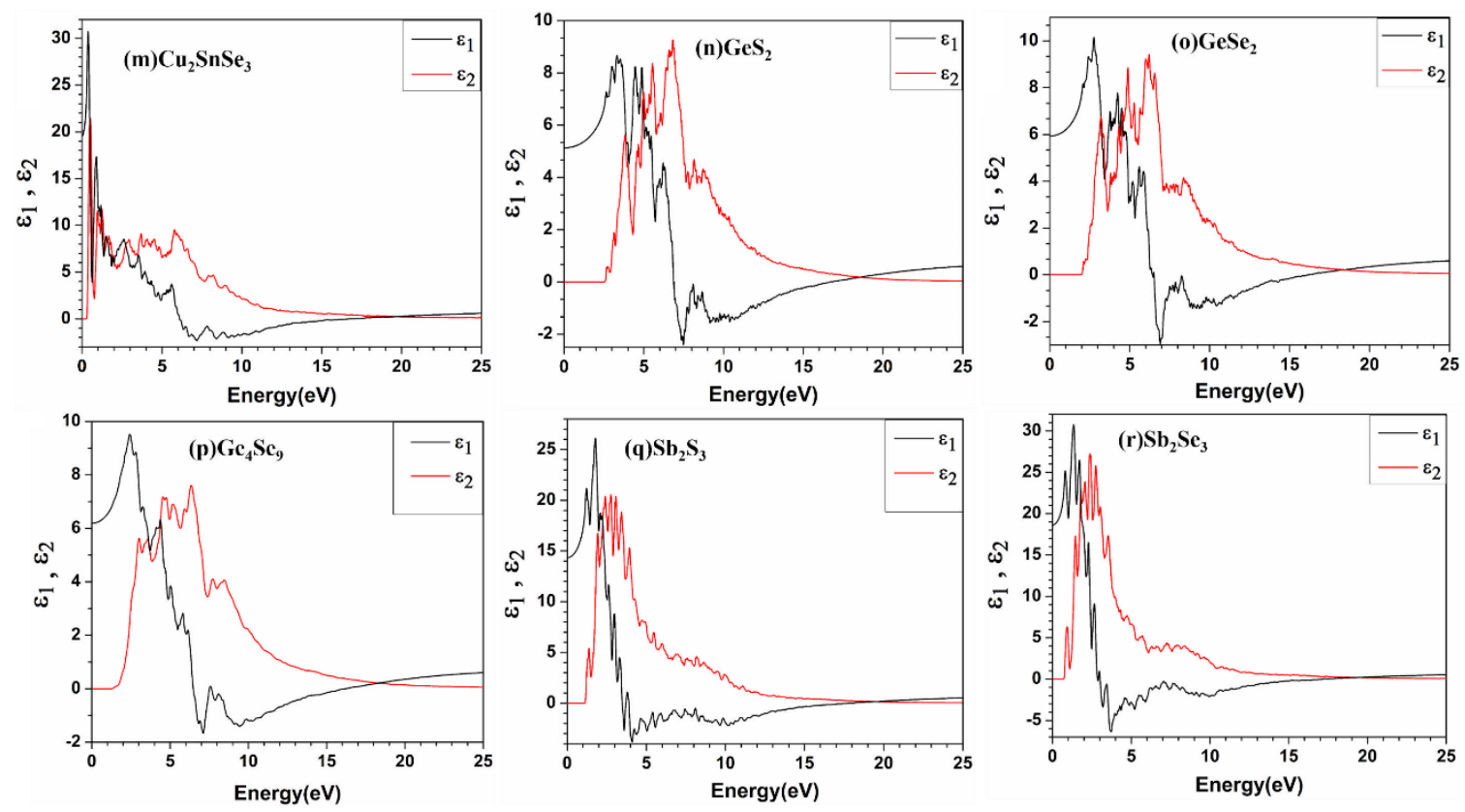

Fig.7. Optical dielectric function for the crystals from (m) $\mathrm{Cu}_{2} \mathrm{SnSe}_{3}$ to (r) $\mathrm{Sb}_{2} \mathrm{Se}_{3}$. The black curve for the real part $\left(\varepsilon_{1}\right)$, the red curve for the imaginary part $\left(\varepsilon_{2}\right)$.
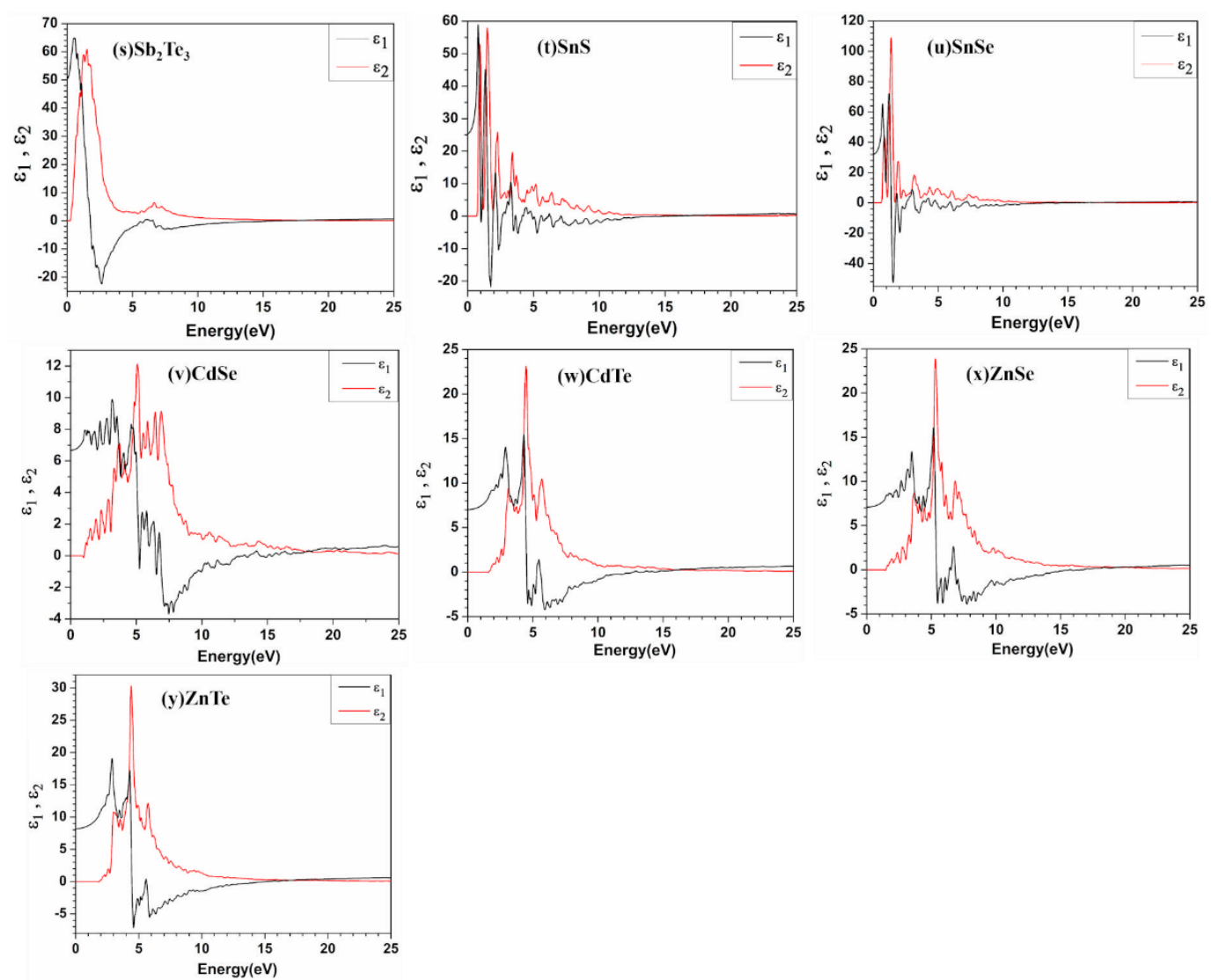

Fig.8. Optical dielectric function for the crystals from (s) $\mathrm{Sb}_{2} \mathrm{Te}_{3}$ to (y) ZnTe. The black curve for the real part $\left(\varepsilon_{1}\right)$, the red curve for the imaginary part $\left(\varepsilon_{2}\right)$.

From the results presented in Figs. 5-8, we see that these chalcogenide crystals in general have high refractive indices of about 5 to 7 . Because of the lack of published results on the optical properties for these crystals, we can only compare with a few of them. Shama et al. [75] calculated the refractive index of $\mathrm{As}_{2} \mathrm{Te}_{3}$ to be 6.83 
which is close to our value of 6.01. For crystalline $\mathrm{Cu}_{2} \mathrm{Te}$, we find an experimental study reporting $n$ to be between $3.0-6.0$ [92] close to what we got $(n=5.470)$. It should be noted that our calculated optical band gap for $\mathrm{Cu}_{2} \mathrm{Te}$ is $0.0 \mathrm{eV}$ which contributed to the large $n$ similar to other chalcogenides just discussed. The refractive index of $\mathrm{Sb}_{2} \mathrm{Te}_{3}$ was recently calculated by Lawal et al. [71] to be 7.482 which again is close to our result of 7.07. Rehman et al. [93] calculated the pressure dependence of the refractive index $n$ of SnSe. The refractive index ranges 3.18 to 8.74 for pressure between 0 to $40 \mathrm{GPa}$. Our calculated value of $n=5.65$ is within this range.

Finally, we present the calculated the energy loss functions (ELF) for all 25 crystals in Figs. S12, S13 and S14). ELF represents the collective excitation of excited electrons at high frequency. It main peak is defined as the plasma frequency $\omega_{\mathrm{p}}$ which usually occurs at the frequency when the real part of dielectric function vanishes $\left(\varepsilon_{1}\left(\omega_{\mathrm{p}}\right)=0\right)$. Below $\omega_{\mathrm{p}}$, the incident waves will be mostly reflected. Above $\omega_{\mathrm{p}}$, the material behave like a plasma, or the excited electrons are nearly free electrons. Table 2 shows the highest $\omega_{\mathrm{p}}$ among the 25 crystals occurs is in $\mathrm{Cu}_{4} \mathrm{GeS}_{4}(20.19 \mathrm{eV})$, while the lowest $\omega_{\mathrm{p}}$ is in $\mathrm{SnSe}$ at $14.99 \mathrm{eV}$.

\subsection{Mechanical properties}

Mechanical properties for chalcogenide crystals are much less studied compared to optical properties. We have calculated the mechanical properties of 25 chalcogenide crystals using the method described in Section 3 in SI. The calculated elastic constants are listed in Table S1 which provide a wealth of information about the stability, stiffness, brittleness, ductility, and anisotropy of these crystals [94]. The principal coefficients $\mathrm{C}_{11}$, $\mathrm{C}_{22}$, and $\mathrm{C}_{33}$ reflects the isotropic elasticity of the crystals and they are very close. $\mathrm{C}_{11}, \mathrm{C}_{22}$, and $\mathrm{C}_{33}$ are related to the unidirectional compression along the principle $\mathrm{x}_{-}, \mathrm{y}-, \mathrm{z}-$ directions [42]. Equivalently, we say $\mathrm{C}_{11}, \mathrm{C}_{22}$, and $\mathrm{C}_{33}$ reflect the resistance of the crystal to the deformation along $\mathrm{x}, \mathrm{y}$, and $\mathrm{z}$ directions. Table S1 shows that $\mathrm{C}_{33}$ is higher than $\mathrm{C}_{11}$ and $\mathrm{C}_{22}$ in some monoclinic crystals such as $\mathrm{Ag}_{2} \mathrm{~S}, \mathrm{Ag}_{2} \mathrm{Se}, \mathrm{As}_{2} \mathrm{~S}_{3}, \mathrm{As}_{2} \mathrm{Se}_{3}, \mathrm{As}_{4} \mathrm{Se}_{4}, \mathrm{Cu}_{2} \mathrm{Se}_{\text {, }}$ and $\mathrm{Cu}_{2} \mathrm{SnSe}_{3}$ which implies that in these crystals, they are more compressible along $\mathrm{x}$ - and y-axes than along z-axis. $C_{22}$ is higher than $\mathrm{C}_{11}$ and $\mathrm{C}_{33}$ in monoclinic crystals $\left(\mathrm{Ag}_{2} \mathrm{Te}, \mathrm{As}_{2} \mathrm{Te}_{3}, \mathrm{Cu}_{2} \mathrm{~S}, \mathrm{GeS}_{2}, \mathrm{GeSe}_{2}, \mathrm{Cu}_{4} \mathrm{SnS}_{4}\right)$ and also in orthorhombic crystals $\left(\mathrm{Ge}_{4} \mathrm{Se}_{9}, \mathrm{Sb}_{2} \mathrm{~S}_{3}, \mathrm{Sb}_{2} \mathrm{Se}_{3}\right.$, and $\left.\mathrm{SnS}\right)$. So these crystals are more compressible along $\mathrm{x}$ - and z-axes than along y-axis. $\mathrm{C}_{11}$ is higher than both $\mathrm{C}_{22}$ and $\mathrm{C}_{33}$ in monoclinic $\mathrm{Cu}_{2} \mathrm{SnS}_{3}$ and $\mathrm{Cu}_{2} \mathrm{Te}$, trigonal $\mathrm{Sb}_{2} \mathrm{Te}_{3}$, orthorhombic SnSe. Accordingly, these crystals are more compressible along $\mathrm{y}$ - and z-axes than along $\mathrm{x}$-axis. For CdSe, CdTe, ZnSe, and ZnTe crystals, $\mathrm{C}_{11}=\mathrm{C}_{22}=\mathrm{C}_{33}$ since the cubic crystals are isotropic.

From elastic constants we can obtain the mechanical parameters: bulk modulus $(\mathrm{K})$, shear modulus $(\mathrm{G})$, Young's modulus (E), and Poisson's ratio ( $\eta$ ) under VRH approximation for polycrystals as explained in Section 3 in SI [95-97]. These values are listed in Table 3. Young's modulus measures the stiffness of the materials, bulk modulus refers to the resistance to shape deformation, and shear modulus reflects the resistance against the shear deformation. Table 3 shows that E can vary widely among the 25 chalcogenide crystals ranging from $5.29 \mathrm{GPa}$ in $\mathrm{As}_{4} \mathrm{Se}_{4}$ to $83.14 \mathrm{in} \mathrm{ZnSe}$, a factor of more than 13 . We are unable to find any previous calculated or experimental elastic properties for several crystals $\left(\mathrm{Ag}_{2} \mathrm{~S}, \mathrm{Cu}_{2} \mathrm{~S}, \mathrm{Cu}_{2} \mathrm{Se}, \mathrm{Cu}_{2} \mathrm{Te}_{\mathrm{Cu}} \mathrm{Cu}_{4} \mathrm{GeS}_{4}, \mathrm{GeS}_{2}\right.$, $\mathrm{GeSe}_{2}$, and $\mathrm{Ge}_{4} \mathrm{Se}_{9}$ ). From the shear and bulk modulus parameters, we can express another important parameter called Pugh's ratio, G/K [98, 99]. According to Pugh's criterion, the crystals with G/K larger than 0.571 are brittle, and those with G/K less than 0.571 are more ductile. Thus the following crystals: $\mathrm{As}_{2} \mathrm{Se}_{3}, \mathrm{As}_{4} \mathrm{Se}_{4}, \mathrm{As}_{2} \mathrm{Te}_{3}$, $\mathrm{Cu}_{2} \mathrm{Te}, \mathrm{GeS}_{2}, \mathrm{Ge}_{4} \mathrm{Se}_{9}, \mathrm{Sb}_{2} \mathrm{~S}_{3}, \mathrm{Sb}_{2} \mathrm{Te}_{3}, \mathrm{SnS}, \mathrm{SnSe}, \mathrm{ZnSe}$ and $\mathrm{ZnTe}$ are brittle, whereas the rest of the 25 crystals are ductile. 
Table 3. Calculated Young modulus (E), Bulk modulus (K), Shear modulus (G), Poisson's ratio ( $\eta$ ), and Pugh's modulus ratio (G/K) for the 25 crystals. For some of these crystals, we did not find any experimental or calculated data for the mechanical properties for comparison.

\begin{tabular}{|c|c|c|c|c|c|}
\hline Crystal & E (GPa) & K (GPa) & G (GPa) & $\eta$ & G/K \\
\hline $\mathrm{Ag}_{2} \mathrm{~S}$-This work & 28.677 & 31.0408 & 10.5227 & 0.346 & 0.338 \\
\hline $\mathrm{Ag}_{2} \mathrm{Se}$ - This work & 23.057 & 41.383 & 8.192 & 0.40 & 0.197 \\
\hline Other calc. & - & $58.0[100]$ & $12.0[100]$ & $0.40[100]$ & \\
\hline $\mathrm{Ag}_{2} \mathrm{Te}$ - This work & 30.983 & 35.879 & 11.423 & 0.35 & 0.318 \\
\hline Other calc. & - & $52.0[100]$ & $14.0[100]$ & $0.37[100]$ & \\
\hline $\mathrm{As}_{2} \mathrm{~S}_{3}$ - This work & 17.7425 & 13.1011 & 6.9617 & 0.2743 & 0.531 \\
\hline Expt. & $16.5[101]$ & $13.8[101]$ & - & $0.30[101]$ & \\
\hline $\mathrm{As}_{2} \mathrm{Se}_{3}-$ This work & 12.104 & 7.5705 & 4.9063 & 0.2335 & 0.648 \\
\hline Other calc. & - & $8.0[100]$ & $4.0[100]$ & $0.25[100]$ & \\
\hline $\mathrm{As}_{4} \mathrm{Se}_{4}-$ This work & 5.2946 & 3.1637 & 2.168 & 0.2211 & 0.685 \\
\hline $\mathrm{As}_{2} \mathrm{Te}_{3}-$ This work & 33.877 & 19.7049 & 13.9588 & 0.2135 & 0.708 \\
\hline Other calc. & $53.1[42]$ & $16.0[100], 41.35[42]$ & $11.0[100], 20.7[42]$ & $0.22[100], 0.286[42]$ & \\
\hline $\mathrm{Cu}_{2} \mathrm{~S}$ - This work & 65.413 & 80.704 & 23.692 & 0.36 & 0.293 \\
\hline $\mathrm{Cu}_{2} \mathrm{Se}$ - This work & 53.567 & 45.027 & 20.575 & 0.30 & 0.456 \\
\hline $\mathrm{Cu}_{2} \mathrm{Te}$ - This work & 42.156 & 22.939 & 17.657 & 0.193 & 0.769 \\
\hline $\mathrm{Cu}_{4} \mathrm{GeS}_{4}-$ This work & 68.963 & 67.616 & 25.926 & 0.33 & 0.383 \\
\hline $\mathrm{Cu}_{2} \mathrm{SnS}_{3}$ - This work & 64.544 & 58.278 & 24.533 & 0.315 & 0.420 \\
\hline Other calc. & - & $66.0[100]$ & $27.0[100]$ & $0.32[100]$ & \\
\hline $\mathrm{Cu}_{2} \mathrm{SnSe}_{3}$ - This work & 57.879 & 64.541 & 21.428 & 0.35 & 0.332 \\
\hline Other calc. & - & $55.0[100]$ & $22.0[100]$ & $0.32[100]$ & \\
\hline $\mathrm{GeS}_{2}$ - This work & 14.3145 & 8.4848 & 5.8732 & 0.2188 & 0.692 \\
\hline $\mathrm{GeSe}_{2}$ - This work & 10.0851 & 6.9706 & 3.9584 & 0.2613 & 0.567 \\
\hline $\mathrm{Ge}_{4} \mathrm{Se}_{9}$ - This work & 10.614 & 6.500 & 4.3222 & 0.227 & 0.664 \\
\hline $\mathrm{Sb}_{2} \mathrm{~S}_{3}$ - This work & 30.566 & 17.973 & 12.562 & 0.21 & 0.698 \\
\hline Other calc. & $118.2[52]$ & $16.0[100], 80.25[52]$ & $9.0[100], 47.11[52]$ & $0.27[100], 0.24[52]$ & \\
\hline $\mathrm{Sb}_{2} \mathrm{Se}_{3}$ - This work & 26.412 & 17.951 & 10.524 & 0.25 & 0.586 \\
\hline Other calc. & $104.52[52]$ & $15.0[100], 70.52[52]$ & $41.54[52]$ & $0.25[52]$ & \\
\hline $\mathrm{Sb}_{2} \mathrm{Te}_{3}$ - This work & 58.201 & 34.948 & 23.805 & 0.22 & 0.681 \\
\hline Other calc. & $55.1[76]$ & $18.0[100], 33.1[76]$ & $13.0[100], 22.5[76]$ & $0.21[100], 0.223[76]$ & \\
\hline SnS- This work & 21.879 & 12.033 & 9.139 & 0.197 & 0.759 \\
\hline Other calc. & - & $24.0[100]$ & $17.0[100]$ & $0.21[100]$ & \\
\hline SnSe- This work & 19.566 & 11.738 & 8.005 & 0.22 & 0.681 \\
\hline Other calc. & - & $24.0[100]$ & $15.0[100]$ & $0.25[100]$ & \\
\hline CdSe- This work & 54.663 & 43.000 & 21.218 & 0.2881 & 0.493 \\
\hline Expt. & - & $53.0[86]$ & - & - & \\
\hline Other calc. & $36.8[33]$ & $45.0[100], 52.2[33]$ & $15.0[100], 13.3[33]$ & $0.35[100], 0.383[33]$ & \\
\hline CdTe- This work & 45.295 & 32.7096 & 17.8438 & 0.2692 & 0.545 \\
\hline Expt. & $38.2[102]$ & $45.5[83]$ & $14.1[102]$ & - & \\
\hline Other calc. & $41.2[33]$ & $35.0[100], 47.5[33]$ & $14.0[100], 15.2[33]$ & $0.33[100], 0.355[33]$ & \\
\hline
\end{tabular}




\begin{tabular}{|c|c|c|c|c|c|}
\hline ZnSe- This work & 83.1365 & 55.8929 & 33.1990 & 0.2521 & 0.594 \\
Expt. & - & $62.5[102]$ & - & - & $0.3[100]$ \\
Other calc. & - & $58.0[100], 56.5[82]$ & $28.0[100]$ & 0.2370 & 0.638 \\
\hline ZnTe- This work & 66.8251 & 42.3494 & 27.0107 & - & \\
Expt. & - & $51.0[102]$ & - & $0.29[100]$ & \\
Other calc. & - & $46.0[100], 43.84[82]$ & $22.0[100]$ & \\
\hline
\end{tabular}

In Fig. 9, we plotted $\mathrm{G}$ versus $\mathrm{K}$ for the 25 data points with different symbols and shapes for each crystal. The slope in this figure represents the Pugh moduli ratio G/K. As can be seen, the data can be classified into three groups. The first group of $\mathrm{Ag}_{2} \mathrm{~S}, \mathrm{Ag}_{2} \mathrm{Se}$, and $\mathrm{Ag}_{2} \mathrm{Te}$ have low $\mathrm{G} / \mathrm{K}$ values of $0.388,0.197$ and 0.318 respectively are very ductile. The second group of crystals $\left(\mathrm{As}_{4} \mathrm{Se}_{4}, \mathrm{As}_{2} \mathrm{X}_{3}(\mathrm{X}=\mathrm{Se}, \mathrm{Te}), \mathrm{Cu}_{2} \mathrm{Te}, \mathrm{GeX}_{2}(\mathrm{X}=\mathrm{S}\right.$, $\mathrm{Se}), \mathrm{Ge}_{4} \mathrm{Se}_{9}, \mathrm{Sb}_{2} \mathrm{X}_{3}(X=\mathrm{S}, \mathrm{Se}, \mathrm{Te}), \mathrm{SnX}(X=\mathrm{S}, \mathrm{Se})$, and $\left.\mathrm{ZnX}(X=\mathrm{Se}, \mathrm{Te})\right)$ lie on the dashed line (1) which means that these crystals have a linear fit as shown by the dashed line number one indicating they are more brittle (except for $\mathrm{As}_{2} \mathrm{~S}_{3}$ and $\mathrm{GeSe}_{2}$ which are ductile crystals). The third group consists of the $5 \mathrm{Cu}$-related crystals: $\mathrm{Cu}_{2} \mathrm{X}, \mathrm{Cu}_{2} \mathrm{SnX}_{3}(\mathrm{X}=\mathrm{S}, \mathrm{Se})$, and $\mathrm{CdX}(\mathrm{X}=\mathrm{Se}, \mathrm{Te})$, these crystals lie on the dashed line (2) referring that these crystals are more ductile (See Table 3 ).

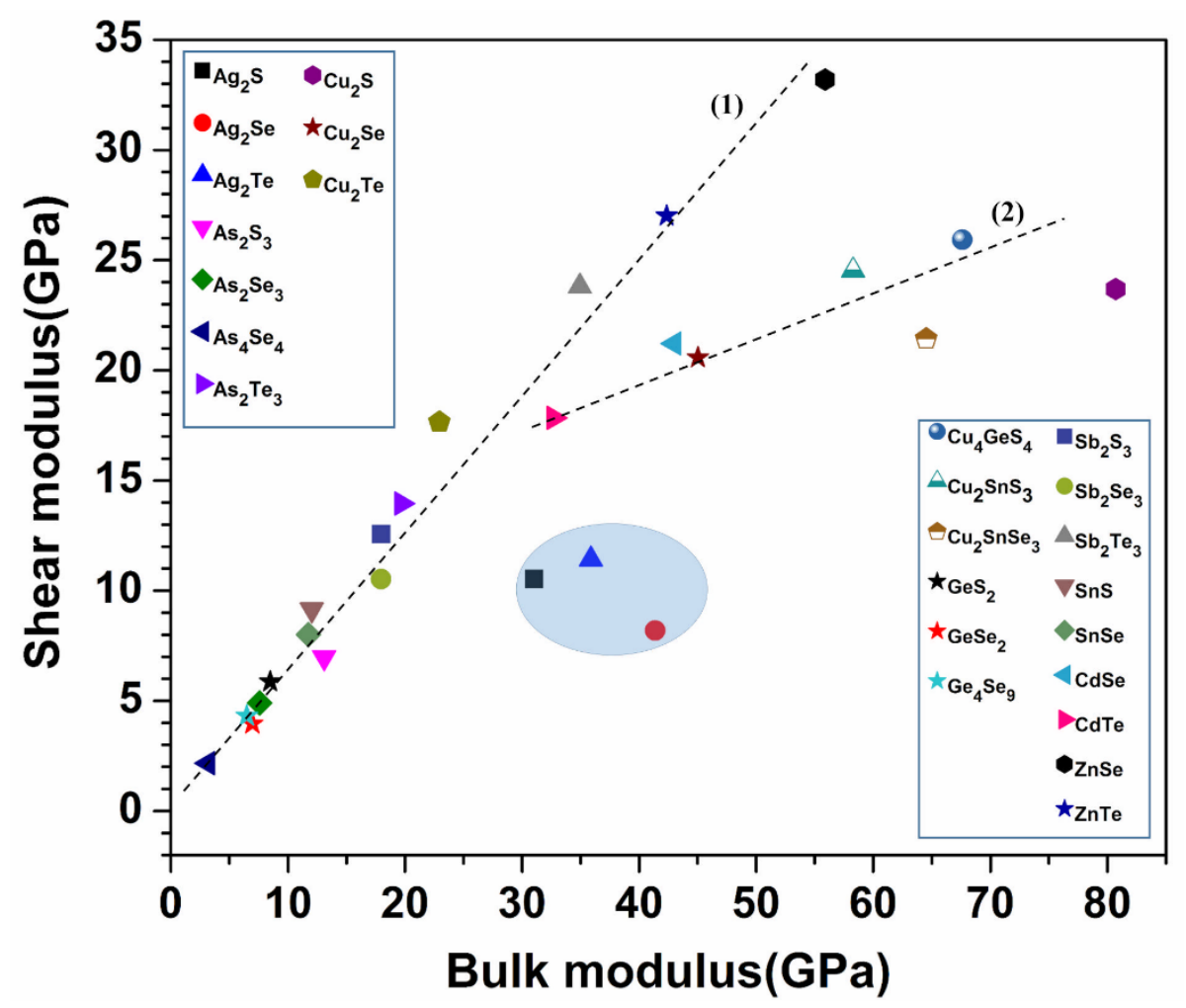

Fig.9. Bulk modulus versus shear modulus for the 25 crystals.

In Fig. 10, we plot the distribution of the Poisson's ratio $\eta$ of 25 crystals. Since Poisson's ratio is closely correlated with the inverse of Pugh modulus ratio, it provides another collaborative evidence to the data presented in Fig. 9. Among the 8 groups according the "A" elements in binary chalcogenides, noble metal Ag and $\mathrm{Cu}$ have high Poisson's ration and roughly similar brittleness. The remaining 6 groups with $\mathrm{A}=\mathrm{As}, \mathrm{Ge}$, $\mathrm{Sb}, \mathrm{Sn}, \mathrm{Cd}$, and $\mathrm{Zn}$ have lower Poisson's ratio and are similar in their ductility. The variations within each group depends on the B elements. Thus one of the major conclusions on the mechanical properties is that 
chalcogenides with noble elements $\mathrm{Ag}$ and $\mathrm{Cu}$ tends to be more brittle and those with $\mathrm{As}, \mathrm{Ge}, \mathrm{Sb}, \mathrm{Sn}, \mathrm{Cd}, \mathrm{Zn}$ are tend to be ductile.

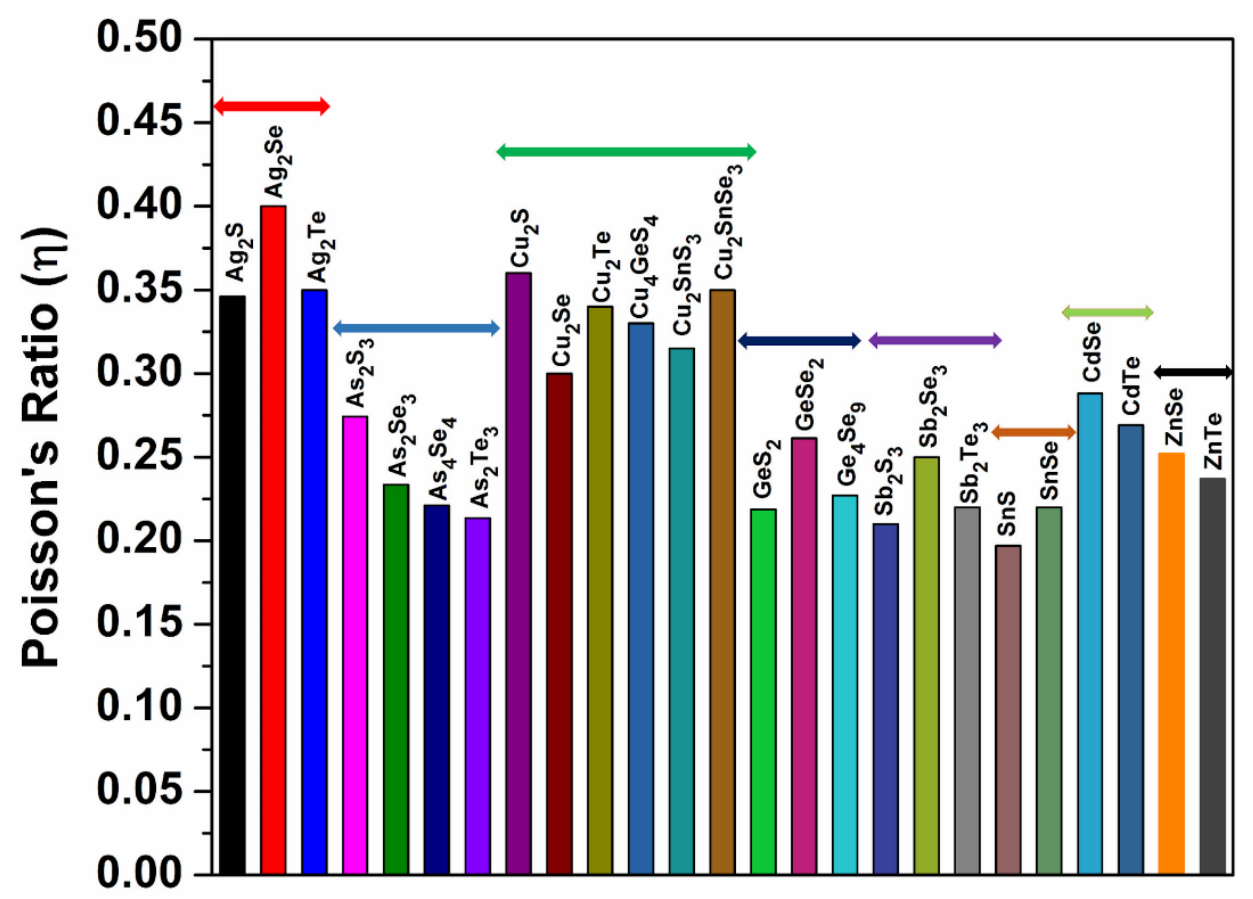

Fig.10. distribution of the calculated Poisson's ratio for the 25 crystals.

We now try to establish the correlation of the calculated mechanical parameters with the TBOD. In Figs. S15, S16, and S17, we plot the Young's modulus, bulk modulus, and shear modulus versus TBOD for the 25 crystals. It is obvious that all three moduli $(\mathrm{E}, \mathrm{K}, \mathrm{G})$ varies with TBOD. Moreover, the correlation for the 25 crystals can be roughly divided into 2 groups. For group 1 crystals $\left(\mathrm{As}_{2} \mathrm{~S}_{3}, \mathrm{As}_{2} \mathrm{Se}_{3}, \mathrm{As}_{2} \mathrm{Te}_{3}, \mathrm{Sb}_{2} \mathrm{~S}_{3}, \mathrm{Sb}_{2} \mathrm{Se}_{3}, \mathrm{Sb}_{2} \mathrm{Te}_{3}, \mathrm{SnS}\right.$, $\mathrm{SnSe}, \mathrm{CdSe}, \mathrm{CdTe}$ ), the E, K, G have similar values of TBOD whereas in group 2 crystals (crystals other than group 1), they steadily increase with TBOD, while ZnSe, ZnTe crystals have the highest E among these 25 crystals. This clearly signals the new insights obtained about the mechanical properties of these 25 chalcogenide crystals. To dig into more details on the correlations between mechanical parameters and the TBOD for the 25 crystals, we plot in Figs. S18, S19, and S20 the E, K, G for 25 crystals into 8 groups in histograms similar to Fig. 3 for TBOD. It is clear that the groups $\left(\mathrm{As}_{2} \mathrm{X}_{3}, X=S, \mathrm{Se}\right.$, and $\left.\mathrm{As}_{4} \mathrm{X}_{4}, \mathrm{X}=\mathrm{Se}\right)$ and $\left(\mathrm{GeX}_{2}, \mathrm{X}=\mathrm{S}, \mathrm{Se}\right)$ have the lowest Young's modulus, while the groups $\left(\mathrm{ZnX}, \mathrm{X}=\mathrm{Se}, \mathrm{Te}, \mathrm{Cu}_{2} \mathrm{X}, \mathrm{X}=\mathrm{S}, \mathrm{Se}, \mathrm{Te}\right.$ and $\mathrm{Cu}_{2} \mathrm{SnX} \mathrm{X}_{2}, \mathrm{X}=\mathrm{S}, \mathrm{Se}$ ) has the highest Young's modulus. We also notice a general feature that $\mathrm{Cu}$ - and $\mathrm{Ag}$-related chalcogenides crystals $\left(\mathrm{Ag}_{2} \mathrm{~S}, \mathrm{Ag}_{2} \mathrm{Se}, \mathrm{Ag}_{2} \mathrm{Te}, \mathrm{Cu}_{2} \mathrm{~S}, \mathrm{Cu}_{2} \mathrm{Se}, \mathrm{Cu}_{2} \mathrm{Te}, \mathrm{Cu}_{4} \mathrm{GeS}_{4}, \mathrm{Cu}_{2} \mathrm{SnS}_{3}\right.$, and $\mathrm{Cu} 2 \mathrm{SnSe} 3$ ) show the higher modulus values than the other crystals.

\section{Conclusions}

Based on the extensive DFT calculation of the electronic structure, interatomic bonding, optical and mechanical properties of the 25 chalcogenide crystals with some of them for the first time, we are able to reveal several new findings and hidden correlations on their properties. We succinctly summarize below the new insights obtained and the conclusions reached in this comprehensive study using the same method and approach, and therefore tend to be more consistent. 
(1) Most of these crystals are semiconductors with small band gaps and few are semimetals. The results for the $\mathrm{Cu}_{4} \mathrm{GeS}_{4}$ and $\mathrm{Ge}_{4} \mathrm{Se}_{9}$ crystals are reported for the first time.

(2) Some of these crystals have very small energy gaps, about $0.015-0.299 \mathrm{eV}$. These include $\mathrm{Cu}_{2} \mathrm{SnSe}_{3}$, $\mathrm{Ag}_{2} \mathrm{Se}, \mathrm{Cu}_{2} \mathrm{~S}, \mathrm{Cu}_{4} \mathrm{GeS}_{4}, \mathrm{Cu}_{2} \mathrm{SnS}_{3}, \mathrm{Sb}_{2} \mathrm{Te}_{3}, \mathrm{SnS}$, and $\mathrm{SnSe}$.

(3) From the calculated bond order values, it is shown that $\mathrm{Cu}-\mathrm{X}, \mathrm{Ge}-\mathrm{X}$, and $\mathrm{Sn}-\mathrm{X}(\mathrm{X}=\mathrm{S}, \mathrm{Se}, \mathrm{Te})$ bonds are much stronger than other interatomic bonds. The binary chalcogenide crystals $\mathrm{A}_{n} \mathrm{~B}_{\mathrm{m}}$ with $\mathrm{A}=\mathrm{Cu}, \mathrm{Zn}$ and $\mathrm{B}=$ $\mathrm{S}, \mathrm{Se}, \mathrm{Te}$ have the highest TBOD.

(4) We also find that the partial charge for $\mathrm{Cu}$ from $\mathrm{Cu}_{2} \mathrm{Te}$ is actually electronegative with corresponding $\mathrm{Te}$ electropositive. This new finding has not been reported previously.

(5) The optical spectra for all 25 crystals are calculated within the random phase approximations and analyzed in detail. They have relatively high refractive index $n$ with some as high as from $5.01-7.07$. This is attributed to the small band gaps with peaks in the real and imaginary dielectric functions at very low energy.

(6) The mechanical properties for these 25 crystals show the difference between those with noble metals (Ag, $\mathrm{Zn}, \mathrm{Cu}$ ) and those with (As, Ge, Sb, Sn, and $\mathrm{Cd}$ ) as the "A" element in the 6 groups. The former is brittle whereas the later is more ductile. They are reasonably correlated with the TBOD thus providing us a new insight never disclosed before.

These results and correlations can help to identify new chalcogenide crystals and glasses for potential new applications especially in optoelectronics. They constitute a reasonable size of the database for chalcogenide crystals. Moreover, the single quantum mechanical metric TBOD and its partial components (PBOD) could be the key descriptors in machine learning protocol for the broader scale design when a big database is available. Such advantage has already been demonstrated in some materials systems other than chalcogenide crystals.

Supplementary Materials: The following are available online at www.mdpi.com/xxx/s1.

Author Contributions: WC initiated the project. SH and KB did the calculation. SH and WC wrote the paper. SH made figures. All authors participated in the discussion and interpretation of the results. All authors edited and proof-the read the final manuscript.

Funding: This research did not receive any specific grant from funding agencies in the public, commercial, or not-for-profit sectors.

Acknowledgments: This research used the resources of the National Energy Research Scientific Computing Center supported by DOE under Contract No. DE-AC03-76SF00098 and also the Research Computing Support Services (RCSS) of the University of Missouri System.

Conflicts of Interest: The authors declare no competing financial interest.

\section{References}

[1] A. Zakery, S.R. Elliott, Optical nonlinearities in chalcogenide glasses and their applications, Springer, 2007. [2] R. Pan, H. Tao, H. Zang, C. Lin, T. Zhang, X. Zhao, Structure and optical properties of amorphous GeSx films prepared by PLD, Journal of Non-Crystalline Solids, 357 (2011) 2358-2361.

[3] N. Sharma, S. Sharda, V. Sharma, P. Sharma, Optical analysis of Ge19Se81- xSbx thin films using single transmission spectrum, Materials Chemistry and Physics, 136 (2012) 967-972. 
[4] M. Abdullah, P. Singh, M. Hasmuddin, G. Bhagavannarayana, M. Wahab, In situ growth and ab initio optical characterizations of amorphous Ga3Se4 thin film: A new chalcogenide compound semiconductor thin film, Scripta Materialia, 69 (2013) 381-384.

[5] A. Al-Ghamdi, S.A. Khan, S. Al-Heniti, F. Al-Agel, M. Zulfequar, Annealing and laser irradiation effects on optical constants of Ga15Se85 and Ga15Se83In2 chalcogenide thin films, Current Applied Physics, 11 (2011) 315-320.

[6] Q. Yan, H. Jain, J. Ren, D. Zhao, G. Chen, Effect of photo-oxidation on photobleaching of GeSe2 and Ge2Se3 films, The Journal of Physical Chemistry C, 115 (2011) 21390-21395.

[7] C.M. Muiva, T.S. Sathiaraj, J.M. Mwabora, Chemical bond approach to optical properties of some flash evaporated Se 100- X Sb X chalcogenide alloys, The European Physical Journal-Applied Physics, 59 (2012).

[8] G. Yang, Y. Gueguen, J.-C. Sangleboeuf, T. Rouxel, C. Boussard-Plédel, J. Troles, P. Lucas, B. Bureau, Physical properties of the GexSe1- $x$ glasses in the $0<x<0.42$ range in correlation with their structure, Journal of NonCrystalline Solids, 377 (2013) 54-59.

[9] L. Liu, T. Cheng, K. Nagasaka, H. Tong, G. Qin, T. Suzuki, Y. Ohishi, Coherent mid-infrared supercontinuum generation in all-solid chalcogenide microstructured fibers with all-normal dispersion, Optics letters, 41 (2016) 392-395.

[10] B. Zhang, W. Guo, Y. Yu, C. Zhai, S. Qi, A. Yang, L. Li, Z. Yang, R. Wang, D. Tang, Low Loss, High NA Chalcogenide Glass Fibers for Broadband Mid-Infrared Supercontinuum Generation, Journal of the American Ceramic Society, 98 (2015) 1389-1392.

[11] X. Dai, X. Liu, L. Liu, B. Zhu, Z. Fang, A novel image-guided FT-IR sensor using chalcogenide glass optical fibers for the detection of combustion gases, Sensors and Actuators B: Chemical, 220 (2015) 414-419.

[12] S.B. Mirov, V.V. Fedorov, D. Martyshkin, I.S. Moskalev, M. Mirov, S. Vasilyev, Progress in mid-IR lasers based on $\mathrm{Cr}$ and Fe-doped II-VI chalcogenides, IEEE Journal of selected topics in quantum electronics, 21 (2015) 292-310.

[13] A. Seddon, M. Laine, Chalcogenide glasses for acousto-optic devices. II. As-Ge-Se systems, Journal of non-crystalline solids, 213 (1997) 168-173.

[14] K. Abe, H. Takebe, K. Morinaga, Preparation and properties of Ge · Ga · S glasses for laser hosts, Journal of non-crystalline solids, 212 (1997) 143-150.

[15] J.-F. Viens, C. Meneghini, A. Villeneuve, T.V. Galstian, E.J. Knystautas, M. Duguay, K. Richardson, T. Cardinal, Fabrication and characterization of integrated optical waveguides in sulfide chalcogenide glasses, Journal of Lightwave Technology, 17 (1999) 1184.

[16] P. Sharma, N. Sharma, S. Sharda, S. Katyal, V. Sharma, Recent developments on the optical properties of thin films of chalcogenide glasses, Progress in Solid State Chemistry, 44 (2016) 131-141.

[17] N. Mehta, Applications of chalcogenide glasses in electronics and optoelectronics: A review, (2006).

[18] J. Rowlands, S. Kasap, Amorphous semiconductors usher in digital x-ray imaging, Physics Today, 50 (1997) 24-30.

[19] U. Neitzel, I. Maack, S. Günther-Kohfahl, Image quality of a digital chest radiography system based on a selenium detector, Medical physics, 21 (1994) 509-516.

[20] D. Babić, S. Rabii, J. Bernholc, Structural and electronic properties of arsenic chalcogenide molecules, Physical Review B, 39 (1989) 10831.

[21] L. Reijnen, B. Meester, A. Goossens, J. Schoonman, Atomic layer deposition of CuxS for solar energy conversion, Chemical Vapor Deposition, 9 (2003) 15-20.

[22] H. Shen, X. Jiao, D. Oron, J. Li, H. Lin, Efficient electron injection in non-toxic silver sulfide (Ag2S) sensitized solar cells, Journal of Power Sources, 240 (2013) 8-13. 
[23] M.-C. Lin, M.-W. Lee, Cu2-xS quantum dot-sensitized solar cells, Electrochemistry Communications, 13 (2011) 1376-1378.

[24] A. Tubtimtae, K.-L. Wu, H.-Y. Tung, M.-W. Lee, G.J. Wang, Ag2S quantum dot-sensitized solar cells, Electrochemistry Communications, 12 (2010) 1158-1160.

[25] T. Nomura, T. Maeda, T. Wada, Preparation of narrow band-gap Cu2Sn (S, Se) 3 and fabrication of film by non-vacuum process, Japanese Journal of Applied Physics, 52 (2013) 04CR08.

[26] Y.-T. Zhai, S. Chen, J.-H. Yang, H.-J. Xiang, X.-G. Gong, A. Walsh, J. Kang, S.-H. Wei, Structural diversity and electronic properties of Cu 2 Sn X 3 (X=S, Se): A first-principles investigation, Physical Review B, 84 (2011) 075213.

[27] Y. Ma, L. Kou, Y. Dai, T. Heine, Two-dimensional topological insulators in group-11 chalcogenide compounds: M 2 Te (M= Cu, Ag), Physical Review B, 93 (2016) 235451.

[28] L. Makinistian, E. Albanesi, First-principles calculations of the band gap and optical properties of germanium sulfide, Physical Review B, 74 (2006) 045206.

[29] T. Schwarzl, M. Böberl, W. Heiss, G. Springholz, J. Fürst, H. Pascher, Comparison of IV-VI Semiconductor Microcavity Lasers for the Mid-Infrared with Active Regions of Different Dimensionality, in: GMe Forum 2003, 2003, pp. 103.

[30] M. Böberl, W. Heiss, T. Schwarzl, K. Wiesauer, G. Springholz, Midinfrared continuous-wave photoluminescence of lead-salt structures up to temperatures of 190 C, Applied physics letters, 82 (2003) 4065-4067.

[31] W. Zhang, R. Yu, H.-J. Zhang, X. Dai, Z. Fang, First-principles studies of the three-dimensional strong topological insulators Bi2Te3, Bi2Se3 and Sb2Te3, New Journal of Physics, 12 (2010) 065013.

[32] Z. Nabi, A. Kellou, S. Mecabih, A. Khalfi, N. Benosman, Opto-electronic properties of rutile SnO2 and orthorhombic SnS and SnSe compounds, Materials Science and Engineering: B, 98 (2003) 104-115.

[33] L. Guo, S. Zhang, W. Feng, G. Hu, W. Li, A first-principles study on the structural, elastic, electronic, optical, lattice dynamical, and thermodynamic properties of zinc-blende $\mathrm{CdX}(\mathrm{X}=\mathrm{S}$, Se, and Te), Journal of Alloys and Compounds, 579 (2013) 583-593.

[34] T.B. Nasr, H. Maghraoui-Meherzi, H.B. Abdallah, R. Bennaceur, First principles calculations of electronic and optical properties of Ag 2 S, Solid State Sciences, 26 (2013) 65-71.

[35] C. Fang, R. De Groot, G. Wiegers, Ab initio band structure calculations of the low-temperature phases of Ag2Se, Ag2Te and Ag3AuSe2, Journal of Physics and Chemistry of Solids, 63 (2002) 457-464.

[36] V. Kaur, S. Tripathi, S. Prakash, The electronic structure of As2S3, in: AIP Conference Proceedings, AIP Publishing, 2016, pp. 020433.

[37] R. Synowicki, T.E. Tiwald, Optical properties of bulk c-ZrO2, c-MgO and a-As2S3 determined by variable angle spectroscopic ellipsometry, Thin Solid Films, 455 (2004) 248-255.

[38] S.K. Sundaram, J.S. McCloy, B.J. Riley, M.K. Murphy, H.A. Qiao, C.F. Windisch Jr, E.D. Walter, J.V. Crum, R. Golovchak, O. Shpotyuk, Gamma radiation effects on physical, optical, and structural properties of binary AsS glasses, Journal of the American Ceramic Society, 95 (2012) 1048-1055.

[39] S. Fayek, M. Balboul, K. Marzouk, Optical, electrical and thermal studies on (As2Se3) 3- x (As2Te3) x glasses, Thin Solid Films, 515 (2007) 7281-7285.

[40] K.A. Aly, Optical band gap and refractive index dispersion parameters of AsxSe70Te30- x (0 $\leq x \leq 30$ at.\%) amorphous films, Applied Physics A, 99 (2010) 913-919.

[41] A. Dahshan, H. Amer, K. Aly, Compositional dependence of the optical constants of amorphous GexAs20Se80- x thin films, Journal of Physics D: Applied Physics, 41 (2008) 215401. 
[42] H. Deng, Theoretical prediction of the structural, electronic, mechanical and thermodynamic properties of the binary $\alpha$-As2Te3 and $\beta$-As2Te3, Journal of Alloys and Compounds, 656 (2016) 695-701.

[43] T. Premkumar, J. Mani, G. Anbalagan, R. Vidya, Electronic Structure Properties of ATe and A 2 Te (A: Cu, $\mathrm{Ag}$ and $\mathrm{Cd}$ ), in: International Workshop on the Physics of Semiconductor and Devices, Springer, 2017, pp. 1151-1157.

[44] M. Råsander, L. Bergqvist, A. Delin, Density functional theory study of the electronic structure of fluorite Cu2Se, Journal of Physics: Condensed Matter, 25 (2013) 125503.

[45] A. Shigemi, T. Maeda, T. Wada, First-principles calculation of Cu2SnS3 and related compounds, physica status solidi (b), 252 (2015) 1230-1234.

[46] S. Blaineau, P. Jund, D.A. Drabold, Physical properties of a GeS 2 glass using approximate ab initio molecular dynamics, Physical Review B, 67 (2003) 094204.

[47] M. Fuentes-Cabrera, H. Wang, O.F. Sankey, Phase stability and pressure-induced semiconductor to metal transition in crystalline GeSe2, Journal of Physics: Condensed Matter, 14 (2002) 9589.

[48] F. Abdel-Wahab, H. El Shaikh, R. Salem, Effect of Sb on the optical properties of the Ge-Se chalcogenide thin films, Physica B: Condensed Matter, 422 (2013) 40-46.

[49] R. Kumar, D. Sharma, V. Rangra, Effect of indium incorporation on the optical properties of Ge-Se glassy semiconductors, OPTOELECTRONICS AND ADVANCED MATERIALS-RAPID COMMUNICATIONS, 5 (2011) 10651068.

[50] P. Sharma, S. Katyal, Effect of substrate temperature on the optical parameters of thermally evaporated Ge-Se-Te thin films, Thin Solid Films, 517 (2009) 3813-3816.

[51] H.M. Kotb, F.M. Abdel-Rahim, The influence of the substitution of Se for Sn on the thermal, optical and dispersion properties of Ge14Se86- xSnx thin films, Materials Science in Semiconductor Processing, 38 (2015) 209-217.

[52] H. Koc, A.M. Mamedov, E. Deligoz, H. Ozisik, First principles prediction of the elastic, electronic, and optical properties of Sb2S3 and Sb2Se3 compounds, Solid State Sciences, 14 (2012) 1211-1220.

[53] B.Y. Yavorsky, N. Hinsche, I. Mertig, P. Zahn, Electronic structure and transport anisotropy of Bi 2 Te 3 and Sb 2 Te 3, Physical Review B, 84 (2011) 165208.

[54] R. Guo, X. Wang, Y. Kuang, B. Huang, First-principles study of anisotropic thermoelectric transport properties of IV-VI semiconductor compounds SnSe and SnS, Physical Review B, 92 (2015) 115202.

[55] M. Safari, Z. Izadi, J. Jalilian, I. Ahmad, S. Jalali-Asadabadi, Metal mono-chalcogenides ZnX and CdX (X= S, Se and Te) monolayers: Chemical bond and optical interband transitions by first principles calculations, Physics Letters A, 381 (2017) 663-670.

[56] N.D. Savchenko, T.N. Shchurova, A.B. Kondrat, V.M. Mitsa, Calculation of Elastic Constants for (GeS 2) x (As 2 S 3) 1-x Glasses, in: AIP Conference Proceedings, AIP, 2007, pp. 1363-1366.

[57] A. Sreeram, A. Varshneya, D. Swiler, Molar volume and elastic properties of multicomponent chalcogenide glasses, Journal of non-crystalline solids, 128 (1991) 294-309.

[58] G. Kresse, Software vasp, vienna, 1999; g. kresse, j. furthmüller, Phys. Rev. B, 54 (1996) 169.

[59] W.-Y. Ching, P. Rulis, Electronic Structure Methods for Complex Materials: The orthogonalized linear combination of atomic orbitals, Oxford University Press, 2012.

[60] J.P. Perdew, K. Burke, M. Ernzerhof, Generalized gradient approximation made simple, Physical review letters, 77 (1996) 3865.

[61] H.J. Monkhorst, HJ Monkhorst and JD Pack, Phys. Rev. B 13, 5188 (1976), Phys. Rev. B, 13 (1976) 5188.

[62] L. Poudel, P. Rulis, L. Liang, W.-Y. Ching, Electronic structure, stacking energy, partial charge, and hydrogen bonding in four periodic B-DNA models, Physical Review E, 90 (2014) 022705. 
[63] K. Baral, P. Adhikari, W.Y. Ching, Ab initio Modeling of the Electronic Structures and Physical Properties of a-Si1- xGexO2 Glass ( $x=0$ to 1), Journal of the American Ceramic Society, 99 (2016) 3677-3684.

[64] R.S. Mulliken, Electronic population analysis on LCAO-MO molecular wave functions. I, The Journal of Chemical Physics, 23 (1955) 1833-1840.

[65] T.B. Nasr, H. Maghraoui-Meherzi, H.B. Abdallah, R. Bennaceur, First principles calculations of electronic and optical properties of Ag2S, Solid State Sciences, 26 (2013) 65-71.

[66] J. Li, D. Drabold, S. Krishnaswami, G. Chen, H. Jain, Electronic Structure of Glassy Chalcogenides As 4 Se 4 and As 2 Se 3: A Joint Theoretical and Experimental Study, Physical review letters, 88 (2002) 046803.

[67] F.B. Romdhane, O. Cretu, L. Debbichi, O. Eriksson, S. Lebègue, F. Banhart, Quasi-2D Cu2S Crystals on Graphene: In-situ Growth and ab-initio Calculations, Small, 11 (2015) 1253-1257.

[68] R. Pan, H. Tao, J. Wang, J. Wang, H. Chu, T. Zhang, D. Wang, X. Zhao, Structure and optical properties of amorphous Ge-Se films prepared by pulsed laser deposition, Optik-International Journal for Light and Electron Optics, 124 (2013) 4943-4946.

[69] J. Ibáñez, J. Sans, C. Popescu, J. López-Vidrier, J. Elvira-Betanzos, V.P. Cuenca-Gotor, O. Gomis, F. Manjón, P. Rodríguez-Hernández, A. Muñoz, Structural, vibrational, and electronic study of Sb2S3 at high pressure, The Journal of Physical Chemistry C, 120 (2016) 10547-10558.

[70] K. Zhao, Y. Wang, Y. Sui, C. Xin, X. Wang, Y. Wang, Z. Liu, B. Li, First principles study of isostructural phase transition in Sb2Te3 under high pressure, physica status solidi (RRL)-Rapid Research Letters, 9 (2015) 379383.

[71] A. Lawal, A. Shaari, R. Ahmed, N. Jarkoni, Sb2Te3 crystal a potential absorber material for broadband photodetector: A first-principles study, Results in physics, 7 (2017) 2302-2310.

[72] S. Guo, L. Yuan, X. Liu, W. Zhou, X. Song, S. Zhang, First-principles study of SO2 sensors based on phosphorene and its isoelectronic counterparts: GeS, GeSe, SnS, SnSe, Chemical Physics Letters, 686 (2017) 83-87.

[73] Z. Nourbakhsh, Structural, electronic and optical properties of ZnX and CdX compounds (X= Se, Te and S) under hydrostatic pressure, Journal of Alloys and Compounds, 505 (2010) 698-711.

[74] J.A. Suárez, J.J. Plata, A.M. Márquez, J.F. Sanz, Structural, electronic and optical properties of copper, silver and gold sulfide: a DFT study, Theoretical Chemistry Accounts, 135 (2016) 70.

[75] Y. Sharma, P. Srivastava, First principles investigation of electronic, optical and transport properties of $\alpha$ and $\beta$-phase of arsenic telluride, Optical Materials, 33 (2011) 899-904.

[76] Q. Xu, B. Huang, Y. Zhao, Y. Yan, R. Noufi, S.-H. Wei, Crystal and electronic structures of Cu x S solar cell absorbers, Applied Physics Letters, 100 (2012) 061906.

[77] Z. Peng, S. Li, M. Weng, M. Zhang, C. Xin, Z. Du, J. Zheng, F. Pan, First-Principles Study of Cu9S5: A Novel p-Type Conductive Semiconductor, The Journal of Physical Chemistry C, 121 (2017) 23317-23323.

[78] A. Crovetto, R. Chen, R.B. Ettlinger, A.C. Cazzaniga, J. Schou, C. Persson, O. Hansen, Dielectric function and double absorption onset of monoclinic Cu2SnS3: Origin of experimental features explained by firstprinciples calculations, Solar Energy Materials and Solar Cells, 154 (2016) 121-129.

[79] R. Chen, C. Persson, Exploring the electronic and optical properties of Cu2Sn1- xGexS3 and Cu2Sn1xSixS3 ( $x=0,0.5$, and 1), physica status solidi (b), 254 (2017) 1700111.

[80] R. Holomb, V. Mitsa, S. Akyuz, E. Akalin, New ring-like models and ab initio DFT study of the mediumrange structures, energy and electronic properties of GeSe2 glass, Philosophical Magazine, 93 (2013) 2549 2562.

[81] T.B. Nasr, H. Maghraoui-Meherzi, N. Kamoun-Turki, First-principles study of electronic, thermoelectric and thermal properties of Sb2S3, Journal of Alloys and Compounds, 663 (2016) 123-127. 
[82] G. Cao, H. Liu, J. Liang, L. Cheng, D. Fan, Z. Zhang, The rhombohedral Sb2Se3 is also an intrinsic topological insulator, arXiv preprint arXiv:1607.05911, (2016).

[83] H. Zhang, Y. Cheng, M. Tang, X. Chen, G. Ji, First-principles study of structural, elastic, electronic and thermodynamic properties of topological insulator Sb2Te3 under pressure, Computational Materials Science, 96 (2015) 342-347.

[84] Y. Kumagai, L.A. Burton, A. Walsh, F. Oba, Electronic Structure and Defect Physics of Tin Sulfides: SnS, Sn 2 S 3, and Sn S 2, Physical Review Applied, 6 (2016) 014009.

[85] Y. Zhang, X. Jia, H. Sun, B. Sun, B. Liu, H. Liu, L. Kong, H. Ma, Effect of high pressure on thermoelectric performance and electronic structure of SnSe via HPHT, Journal of Alloys and Compounds, 667 (2016) 123 129.

[86] N. Data, Functional Relationships in Science and Technology, Group III, 17 (1982).

[87] Z. Zhao, S. Wang, A.R. Oganov, P. Chen, Z. Liu, W.L. Mao, Tuning the crystal structure and electronic states of Ag 2 Se: Structural transitions and metallization under pressure, Physical Review B, 89 (2014) 180102.

[88] J.-B. Vaney, J.-C. Crivello, C. Morin, G. Delaizir, J. Carreaud, A. Piarristeguy, J. Monnier, E. Alleno, A. Pradel, E.B. Lopes, Electronic structure, low-temperature transport and thermodynamic properties of polymorphic $\beta$ As 2 Te 3, RSC Advances, 6 (2016) 52048-52057.

[89] J. Olson, H. Li, T. Ju, J. Viner, P. Taylor, Optical properties of amorphous GeTe, Sb 2 Te 3, and Ge 2 Sb 2 Te 5: the role of oxygen, Journal of applied physics, 99 (2006) 103508.

[90] L.-D. Zhao, S.-H. Lo, Y. Zhang, H. Sun, G. Tan, C. Uher, C. Wolverton, V.P. Dravid, M.G. Kanatzidis, Ultralow thermal conductivity and high thermoelectric figure of merit in SnSe crystals, Nature, 508 (2014) 373.

[91] C. Dharmawardhana, A. Misra, W.-Y. Ching, Quantum mechanical metric for internal cohesion in cement crystals, Scientific reports, 4 (2014) 7332.

[92] D. Ferizović, M. Muñoz, Optical, electrical and structural properties of Cu2Te thin films deposited by magnetron sputtering, Thin Solid Films, 519 (2011) 6115-6119.

[93] S. ur Rehman, F.K. Butt, Z. Tariq, F. Hayat, R. Gilani, F. Aleem, Pressure induced structural and optical properties of cubic phase SnSe: An investigation for the infrared/mid-infrared optoelectronic devices, Journal of Alloys and Compounds, 695 (2017) 194-201.

[94] S. Boucetta, Theoretical study of elastic, mechanical and thermodynamic properties of MgRh intermetallic compound, Journal of Magnesium and Alloys, 2 (2014) 59-63.

[95] W. Voigt, Lehrbuch der kristallphysik (mit ausschluss der kristalloptik), edited by bg teubner and jw edwards, leipzig berlin, Ann Arbor, Mich, (1928).

[96] A. Reuss, Berechnung der fließgrenze von mischkristallen auf grund der plastizitätsbedingung für einkristalle, ZAMM-Journal of Applied Mathematics and Mechanics/Zeitschrift für Angewandte Mathematik und Mechanik, 9 (1929) 49-58.

[97] R. Hill, The elastic behaviour of a crystalline aggregate, Proceedings of the Physical Society. Section A, 65 (1952) 349.

[98] S. Pugh, XCII. Relations between the elastic moduli and the plastic properties of polycrystalline pure metals, The London, Edinburgh, and Dublin Philosophical Magazine and Journal of Science, 45 (1954) 823-843. [99] D. Varshney, S. Jain, S. Shriya, R. Khenata, High-pressure and temperature-induced structural, elastic, and thermodynamical properties of strontium chalcogenides, Journal of Theoretical and Applied Physics, 10 (2016) 163-193.

[100] M. De Jong, W. Chen, T. Angsten, A. Jain, R. Notestine, A. Gamst, M. Sluiter, C.K. Ande, S. Van Der Zwaag, J.J. Plata, Charting the complete elastic properties of inorganic crystalline compounds, Scientific data, 2 (2015) 150009. 
[101] T. Rouxel, Elastic properties and short-to medium-range order in glasses, Journal of the American Ceramic Society, 90 (2007) 3019-3039.

[102] H. McSkimin, D. Thomas, Elastic moduli of cadmium telluride, Journal of Applied Physics, 33 (1962) 5659. 